\title{
Potential Utility of Retinal Imaging for Alzheimer's Disease: A Review
}

\author{
Huan Liao ${ }^{1,2+}$, Zhuoting Zhu ${ }^{3 * t}$ and Ying Peng ${ }^{1,2 *}$ \\ ${ }^{1}$ Department of Neurology, Sun Yat-sen Memorial Hospital, Sun Yat-sen University, Guangzhou, China, ${ }^{2}$ Guangdong \\ Provincial Key Laboratory of Malignant Tumor Epigenetics and Gene Regulation, Sun Yat-sen Memorial Hospital, Sun \\ Yat-sen University, Guangzhou, China, ${ }^{3}$ State Key Laboratory of Ophthalmology, Zhongshan Ophthalmic Center, Sun \\ Yat-sen University, Guangzhou, China
}

The ensuing upward shift in demographic distribution due to the increase in life expectancy has resulted in a rising prevalence of Alzheimer's disease (AD). The heavy public burden of $A D$, along with the urgent to prevent and treat the disease before the irreversible damage to the brain, calls for a sensitive and specific screening technology to identify high-risk individuals before cognitive symptoms arise. Even though current modalities, such as positron emission tomography (PET) and cerebrospinal fluid (CSF) biomarker, showed their potential clinical uses in early detection of $A D$, the high cost, narrow isotope availability of PET probes and invasive characteristics of CSF biomarker limited their broad utility. Therefore, additional tools for detection of AD are needed. As a projection of the central nervous system (CNS), the retina has been described as a "window to the brain" and a novel marker for AD. Low cost, easy accessibility and

OPEN ACCESS

Edited by:

Changiz Geula,

Northwestern University,

United States

Reviewed by:

Arun Bokde,

Trinity College Dublin, Ireland

Claudio Liguori,

Università degli Studi di Roma "Tor

Vergata", Italy

*Correspondence:

Zhuoting Zhu

zhuoting_zhu@hotmail.com

Ying Peng

docpengy123@163.com

${ }^{\dagger}$ These authors have contributed

equally to this work.

Received: 17 March 2018 Accepted: 05 June 2018

Published: 22 June 2018

Citation:

Liao H, Zhu Z and Peng Y (2018) Potential Utility of Retinal Imaging

for Alzheimer's Disease: A Review.

Front. Aging Neurosci. 10:188.

doi: 10.3389/fnagi.2018.00188 non-invasive features make retina tests suitable for large-scale population screening and investigations of preclinical AD. Furthermore, a number of novel approaches in retina imaging, such as optical coherence tomography (OCT), have been developed and made it possible to visualize changes in the retina at a very fine resolution. In this review, we outline the background for $A D$ to accelerate the adoption of retina imaging for the diagnosis and management of $A D$ in clinical practice. Then, we focus on recent findings on the application of retina imaging to investigate $A D$ and provide suggestions for future research directions.

Keywords: Alzheimer's disease, retinal imaging, early detection, novel biomarker, review

\section{INTRODUCTION}

Life expectancy has increased substantially during past few decades, mainly attributable to advancements of health care and lifestyle. The ensuing upward shift in demographic distribution has resulted in a rising prevalence of aging-related diseases, such as dementia. According to the report in Prince et al. (2015), dementia affects approximately 46.8 million people worldwide. AD,

\footnotetext{
Abbreviations: $A \beta$ : amyloid- $\beta$; $A \beta P P$ : amyloid- $\beta$ precursor protein; AD: Alzheimer's disease; AMD: age-related macular degeneration; BBB, blood-brain barrier; BRB, blood-retinal barrier; CFS, cerebrospinal fluid; CNS, central nervous system; CRAE, central retinal arterial equivalent; cSLO, confocal scanning laser ophthalmoscopy; DARC, detection of apoptotic retinal cells; GC-IPL, ganglion cell-inner plexiform layer; GCC: ganglion cell complex; MAP, microtubule-associated protein; MCI, mild cognitive impairment; MMSE, mini mental state examination; MRI, magnetic resonance imaging; OCT, Optical coherence tomography; ONH, optic nerve head; PERG, pattern electroretinogram; PET, positron emission tomography; PWV, pulse wave velocity; RGCs, retinal ganglion cells; RNFL, retinal nerve fiber layer; SD-OCT, spectral-domain OCT; SS-OCT, swept source OCT; TD-OCT, time-domain OCT.
} 
as the most prevalent type of senile dementia by far, accounts for $60-80 \%$ of all cases with dementia (Prince et al., 2015). The prevalence of $\mathrm{AD}$ is estimated to quadruple and intensive health care will be needed for $43 \%$ of these patients by 2050 (Brookmeyer et al., 2007).

Despite of the heavy public disease burden of $\mathrm{AD}$, there is no effective treatment for $\mathrm{AD}$. Advances in the effective treatment and prevention of $\mathrm{AD}$ have been hampered by challenges in diagnosing the disease at the preclinical phase, in which subjects are still asymptomatic in clinical settings but may have subtle evidence of early cognitive deficits in the context of neuropathology specific to AD (Sperling et al., 2011a). Currently, diagnosis was primarily based on cognitive assessments among patients with symptomatic cognitive and behavior deficits (Dubois et al., 2014). Studies suggested that measurable changes in PET, MRI and CSF biomarkers occurred predates the onset of clinical symptoms (Beckett et al., 2010). Unfortunately, these are costly and/or invasive procedures that are not appropriate for screening at a population level.

As a projection of the CNS via the optic nerve, the retina has been described as a "window to the brain" and investigated intensively the potential of serving as a marker for $\mathrm{AD}$ (Guo et al., 2010; MacCormick et al., 2015). Low cost, easy accessibility and non-invasive features make retina tests suitable for largescale population screening and investigations of preclinical AD. Furthermore, a number of novel approaches in retina imaging, such as OCT, have been developed and made it possible to visualize lesions and changes of the retina at a very fine resolution.

In this review, we outline the background for $\mathrm{AD}$ to accelerate the adoption of retina imaging for the diagnosis and management of $\mathrm{AD}$ in clinical practice. Then, we focus on recent findings on the application of retina imaging to investigate $\mathrm{AD}$ and provide suggestions for future research directions.

\section{CHALLENGES FOR EARLY DETECTION OF AD}

In 1906, Alois Alzheimer was credited with identifying the first condition of dementia, which was later to carry his name as $\mathrm{AD} . \mathrm{AD}$ is a progressive neurodegenerative disease, in which synaptic and neuronal loss(Terry et al., 1987; Polanco et al., 2018) lead to irreversible deterioration in memory loss, cognitive impairment and behavioral deficits(Ghiso et al., 2013). Wellknown pathological hallmark related to $\mathrm{AD}$ is the propensity of proteins to form toxic oligomers and fibrils (Jahn et al., 2010). The two key proteins related to $A D$ are $A \beta$ peptide and hyper-phosphorylated tau (Masters et al., 1985; GrundkeIqbal et al., 1986). A $\beta$ peptide is a small peptide deprived from its parent molecule, the amyloid- $\beta$ precursor protein $(\mathrm{A} \beta \mathrm{PP})$, and accumulates of $\mathrm{A} \beta$ into extracellular amyloid senile plaques (Polanco et al., 2018). Hyper-phosphorylated tau is a MAP that accumulates intraneuronally to form neurofibrillary tangles (Moore et al., 2016). Consistent evidences have demonstrated that neuropathologial changes, mainly the accumulation of $A \beta$ and tau, predate the emergence of clinical symptoms by as long as $15-20$ years, emphasizing the potential of developing methods for early diagnosis (Holtzman et al., 2011).

According to the National Institute of Neurological and Communicative Disorders and Stroke and the Alzheimer's Disease and Related Disorders Association criteria (McKhann et al., 1984), the first definition for diagnosis of $\mathrm{AD}$ is relied on neuropathological analysis of brain tissue, obtained by biopsy or autopsy, for the accumulation of $A \beta$ peptides and tau protein. In the following decades, advances in the early diagnosis of $\mathrm{AD}$ have been hampered by challenges in differentiating earliest stage of $\mathrm{AD}$ with age-related cognitive deficit and other forms of dementia. Furthermore, AD is currently diagnosed by cognitive assessments among patients with symptomatic cognitive and behavior deficits (Dubois et al., 2014), which is usually the advanced stage and irreversible to treatment. Despite of enormous financial and scientific efforts, the treatment of $\mathrm{AD}$ has remained symptom-driven and no single disease-modifying therapy for $\mathrm{AD}$ has been approved. So far, it has been documented the high failure rate - nearly $90 \%$ - of clinical drug trials for $\mathrm{AD}$. One of possible reasons for the high failure rate might be the inclusion of patients with the uncertainty diagnosis and/or latestage disease (Sperling et al., 2011b; James et al., 2015; Jellinger and Attems, 2015). Two phase 3 clinical trials(Doody et al., 2014; Salloway et al., 2014) investigated the anti- $\mathrm{A} \beta$ antibody's effect on the treatment of mild-to-moderate AD. Neither study showed a significant benefit of solanezumab (Doody et al., 2014) or bapineuzumab (Salloway et al., 2014) for primarily designated outcomes. However, with sub-analysis of participants with mild $\mathrm{AD}$, half of the prespecified endpoints was met and cognitive deficits were slowed by $34 \%$ (Siemers et al., 2016), suggesting the therapy may be effective in treating the early course of $\mathrm{AD}$. A recent phase $1 \mathrm{~b}$ randomized trial of monthly intravenous infusion of the anti- $\mathrm{A} \beta$ antibody abucanumab in patients with prodromal or mild AD did not have enough power to detect clinical change, however, post hoc analysis suggested the reduction of $A \beta$ burden in brain and a stabilization of cognitive decline based on Clinical Dementia Rating-Sum of Boxes and Mini Mental State Examination scores (Sevigny et al., 2016). Modeling has suggested that interventions aimed at clearing $A \beta$ accumulation may be sufficient to delay the onset of clinically manifest $\mathrm{AD}$, reduce the incidence and the progression of $\mathrm{AD}$ if started in the early stages of AD (Brookmeyer et al., 1998). These findings again stress the importance of early detection of $\mathrm{AD}$.

The increasing global prevalence of $\mathrm{AD}$, along with the urgent to prevent and treat the disease before the irreversible damage to the brain, calls for a sensitive and specific screening strategy to identify individuals at high risk of $\mathrm{AD}$ before cognitive symptoms arise. A large number of novel methods for diagnosis of $\mathrm{AD}$ have been developed during the past decades. Noninvasive neuroimaging tools such as MRI can detect subclinical structural brain changes (e.g., atrophy) related to the future risk of $\mathrm{AD}$. However, due to limited spatial resolution, MRI measures may not be able to detect subtle changes at the early stages. Although specific neuropathology biomarkers, such as the detection of $\mathrm{A} \beta$ and tau accumulation measured by PET imaging (James et al., 2015; Dubois et al., 2016) and in CSF 
(Bateman et al., 2012; Fagan et al., 2014) can be detected predates the onset of clinical symptoms and have shown high specificity in confirming AD pathophysiology (Beckett et al., 2010; Dubois et al., 2014), the high cost, narrow isotope availability of PET probes and invasive characteristics of CSF biomarkers limited their broad usages.

Therefore, additional tools for detection of $\mathrm{AD}$ are needed, with the aim of changing from an exclusionary approach to an accuracy diagnosis, from late-stage symptomatic diagnosis to the subclinical pathology detection, and using in largescale population screening to identify individuals at high risk of developing $\mathrm{AD}$. As the projection of CNS, the retina has attracted researchers' attention to study $\mathrm{AD}$ and its pathology. A large number of studies have employed retina imaging for early detection and large-scale population screening of $\mathrm{AD}$, and considerable progresses have been achieved in recent years.

\section{The Retina - A "Window to AD"}

As an extension of the CNS, the retina and optic nerve share many features in terms of embryological origin, anatomy, response to injury, immunology and physiological characteristics, with the brain (London et al., 2013). The retina and optic nerve originate from the diencephalon during embryonic development, and therefore are considered as an extension of the CNS. Photoreceptor cells of the retina capture light and initiate neuronal signals that eventually reach the RGCs. The optic nerve composed of the axons of RGCs passes the visual information to the higher visual processing centers in the brain. RGCs show the typical patterns of CNS neurons and comprise a cell body, dendrites and an axon. Similar to all fiber tracts of CNS, the optic nerve is myelinated as they leave the eyes. Insult to the optic nerve leads to degeneration of the axons, myelin damage and inducing a neurotoxic condition, which are also observed in other CNS axons (Faden and Salzman, 1992; Schwartz et al., 1996; Crowe et al., 1997; Yoles and Schwartz, 1998; Levkovitch-Verbin et al., 2001, 2003). After injury, similar limited regeneration environment exists in the retina, optic nerve and other CNS compartments. The eye and the brain normally maintain strict interactions with immune system, and both are immune-privileged organs. Furthermore, ocular inner BRB resembles the BBB strongly with respect to structures, characteristics and mechanisms (Kaur et al., 2008).

\section{RETINAL CHANGES AND AD}

Given these strong connections between the brain and the retina, it has been indicated that neurodegenerative disease, such as AD, may also lead to similar pathology in RGCs and optic nerve. The retina and brain are directly connected by axons of the optic nerve, which facilitate transportation of APP synthesized in RGCs in small transport vesicles (Morin et al., 1993). Furthermore, retinal neurons and glia express proteins that have participated in the amyloid cascade (e.g., BACE1, $\gamma$-secretase, APOE) (Cai et al., 2012; Li et al., 2016; Vecino et al., 2016). Several studies verified the presence of classical biomarkers of $\mathrm{AD}, \mathrm{A} \beta$ and tau, within the retina and optic nerve at the molecular level (Gasparini et al., 2011; Koronyo-Hamaoui et al., 2011). Retinal $A \beta$ deposits triggers breakdown of RPE tight junction (Park et al., 2014) and integrity of the blood-retina barrier (Dinet et al., 2012), increases reactive oxygen species production (Bruban et al., 2009), and activates complement by upregulating factor B (Wang et al., 2009). The crucial roles of Tau played in retina include regulating the cytoskeletal and axonal transport in retinal neurons, increasing $A \beta$ accumulation and affecting cell survival signaling in the retina (Ho et al., 2012). Therefore, the toxic effects of these deposits include the apoptosis of the RGCs, thinning of the RNFL, morphological changes in the optic nerve, and other retinal structural and functional impairment of AD patients (Hinton et al., 1986; Tsai et al., 1991; Hedges et al., 1996; Danesh-Meyer et al., 2006; Iseri et al., 2006; Paquet et al., 2007; Ning et al., 2008; Perez et al., 2009; Parnell et al., 2012; Garcia-Martin et al., 2014; Salobrar-Garcia et al., 2015). Studies using animal models of $\mathrm{AD}$ have demonstrated that $\mathrm{A} \beta \mathrm{PP}$ and $\mathrm{A} \beta$ were accumulated in all six layers of the neuroretina (Liu et al., 2009), with the extent proportional to the increasing age of the animal models. Furthermore, animal models have shown that retinal senile plaques were correlated with plaque load in the brain (Koronyo et al., 2012) and were detected prior to the plaque deposition in the brain, implying that $A \beta$ deposition seen in the retina could be an early related sign of $\mathrm{AD}$ detection (ZhangNunes et al., 2006; Koronyo-Hamaoui et al., 2011). In addition, hyperphosphorlylated tau has been reported to accumulate in the RNFL of transgenic AD mouse models, which results in disruption of axonal transport and ganglion cell degeneration (Gasparini et al., 2011; Bull et al., 2012).

It has been suggested that $\mathrm{AD}$ might also be a disease of the neurovascular unit indicated from results of cerebral amyloid angiopathy, focal lesions in brain microcirculation system and strong associations between vascular changes of AD with typical neuronal degenerative changes (Zlokovic, 2011). The overproduction of $A \beta$ in the retinal vascular increases the mechanical stress to endothelial cell regulation of $\mathrm{A} \beta \mathrm{PP}$, with associated destruction of the vessel walls, leading to changes of vascular diameters and topology (Golzan et al., 2017). A large body of evidences have also verified potential associations between $\mathrm{AD}$ and retinal vascular parameters, both static and dynamic, such as retinal vascular diameters, retinal pulsatility and local arterial PWV (Berisha et al., 2007; Pase et al., 2012; Frost et al., 2013; Feke et al., 2015; Williams et al., 2015). Transgenic animal models of $\mathrm{AD}$ have shown $\mathrm{A} \beta$ and senile plaques accumulation in retinal vasculature (Zhang-Nunes et al., 2006; Liu et al., 2009).

\section{IMAGING RETINA TO STUDY AD}

The visualization of detailed structure and functions of the retina has dramatically improved with the development of modern imaging techniques. This has provided clinicians and 
researchers with valuable tools for potential early diagnosis and differentiation, monitoring progression, and clinical drug trials of $\mathrm{AD}$ (Table 1).

\section{STRUCTURAL IMAGING METHODS}

\section{Ocular Fundus or Retinal Photography}

Ocular fundus or retinal photography is the classic imaging technique for investigating the retina, providing routine retinal checks in eye clinics. Ocular fundus or retinal photography is able to detect three types of retinal vascular signs: (1) qualitative retinopathy and retinal arteriolar signs, (2) changes in retinal vascular caliber and (3) changes in global geometrical patterns of the retina (Cheung et al., 2012a).

Large number of studies have documented that qualitative retinal vascular signs and quantitative vascular measures, including retinopathy, vascular reduction, increasing variability of vessel width, attenuate complexity of branching characteristic, reduced optimality of the branching geometry and less tortuous venules, are associated with poorer cognitive performance based on different neuropsychological tests (Patton et al., 2007; Liew et al., 2009; Ding et al., 2011; Kim et al., 2011; Cheung et al., 2012b; Gatto et al., 2012; Ong et al., 2014; Taylor et al., 2015). The Rotterdam Study found that retinopathy was associated with $\mathrm{AD}$ in a cross-sectional population-based sample of individuals aged 55 years and older, whereas longitudinal data from the same study showed no association with incident AD (Schrijvers et al., 2012). Retinopathy was not significantly associated with $\mathrm{AD}$ when investigated in the Cardiovascular Health Study (Baker et al., 2007) and the AGES-Reykjavik Study (Qiu et al., 2010). With respect to AMD, Williams et al. (2014) showed an association between the most advanced cases and $\mathrm{AD}$, whereas the association was lost after adjustment for confounding variables. Similarly, Klaver et al. (1999) found that risk of $\mathrm{AD}$ increased for patients with advanced stage AMD after 25.2 months follow up. However, the association was not significant following adjustment for smoking and atherosclerosis. In terms of the morphology of the $\mathrm{ONH}$, a significant correlation of the optic neuropathy with the onset, severity and duration of $\mathrm{AD}$ was confirmed previously (Tsai et al., 1991; Hedges et al., 1996). With CRAE as an index of vessel caliber, data from the three studies (Frost et al., 2013; Cheung et al., 2014; Williams et al., 2015) were pooled and indicated a reduction in arteriolar width in $\mathrm{AD}$. Increasing standard deviation of microvascular widths and microvascular attenuation in $\mathrm{AD}$ were found using different measures of arteriolar and venular caliber (Frost et al., 2013; Cheung et al., 2014). Three case-control studies (Frost et al., 2013; Cheung et al., 2014; Williams et al., 2015) examined the link between retinal geometric branching parameters, such as fractal dimensions, branching patterns and tortusity in $\mathrm{AD}$ patients. Findings from these studies reported consistent significant reduced venular, arteriolar, and total fractal dimensions, indicating a sparser network in AD (Figure 1). These studies have also consistently shown reduced complexity and optimality of the branching pattern. However, results of tortusity were mixed when compared $\mathrm{AD}$ patients with control subjects. In addition, $\mathrm{AD}$ patients' fundus images illustrated different patterns of RNFL abnormalities, including diffuse and wedge shape RNFL drop-out (Lu et al., 2010).

Current software programs for quantitative measurement of retinal vasculature in routine retinal image are not fully automated and therefore additional efforts are needed by technicians and clinicians. Novel software programs are being developed to fully automatically measure ocular fundus features such as calibers, tortuosity and network complexity, facilitating a more efficient assessment (Cheung and Wong, 2012; Nguyen et al., 2013; Joshi et al., 2014; Cavallari et al., 2015; Abramoff et al., 2016; Walton et al., 2016). In addition, with the advent of the nonmydriatic ultra-wide field retinal imaging technology, up to $200^{\circ}$, rather than the common $45^{\circ}$ or $60^{\circ}$, of the retina can be captured in a single shot for investigating peripheral lesions (Kernt et al., 2012), which may provide a more comprehensive picture of the overall retinal vascular structure and retina (Cheung et al., 2010). A very recent pilot study using ultra-wide field retinal imaging identified peripheral biomarkers, including markedly increased drusen number, significant increase in venular width gradient and significant decrease in arterial fractal dimension, for $\mathrm{AD}$ and its progression over 2 years (Csincsik et al., 2018) (Figure 2).

It is noteworthy that the association between retinal changes with cognitive impairment and $\mathrm{AD}$ is weak and non-specific (Heringa et al., 2013), partly due to the nature variation of retinal vascular parameters and common retinal lesions shared by many diseases, which may limit the usage of a single ocular fundus photography screening test for $\mathrm{AD}$. However, it is possible that longitudinal analysis of retinal changes might be a potential tool to accurately detect preclinical $\mathrm{AD}$ or monitor AD. Further longitudinal studies are thus needed to explore this possibility and determine time course of retinal changes in $\mathrm{AD}$.

\section{Optical Coherence Tomography (OCT)}

Optical coherence tomography, a non-invasive technique providing high-resolution imaging of retina based on the principle of low coherence interferometry (Huang et al., 1991; Puliafito et al., 1995), has been extensively used to evaluate the morphological changes of the retina, such as peripapillary RNFL, macular thickness and volume, in $\mathrm{AD}$. In line with the findings from post mortem studies, studies using OCT demonstrated a significant decline in peripapillary RNFL, and changes in macular thickness and volume in the eyes of patients that are progressive from MCI to AD. Results from two recent meta analysis (Coppola et al., 2015; Thomson et al., 2015) indicated that the attenuation in RNFL thickness, as observed in most studies, was significantly greater both in $\mathrm{AD}$ and MCI patients than that observed in the age-matched healthy controls. The mean RNFL thickness was confirmed to be reduced in $\mathrm{AD}$ and MCI patients in all quadrants (Parisi et al., 2001; Iseri et al., 2006; Paquet et al., 2007; Kesler et al., 2011; Kang and Kim, 2013; Kirbas et al., 2013; Ascaso et al., 2014; Polo et al., 2014; Gunes et al., 2015), but some studies reported reduction of RNFL thickness predominantly in the superior (Parisi et al., 


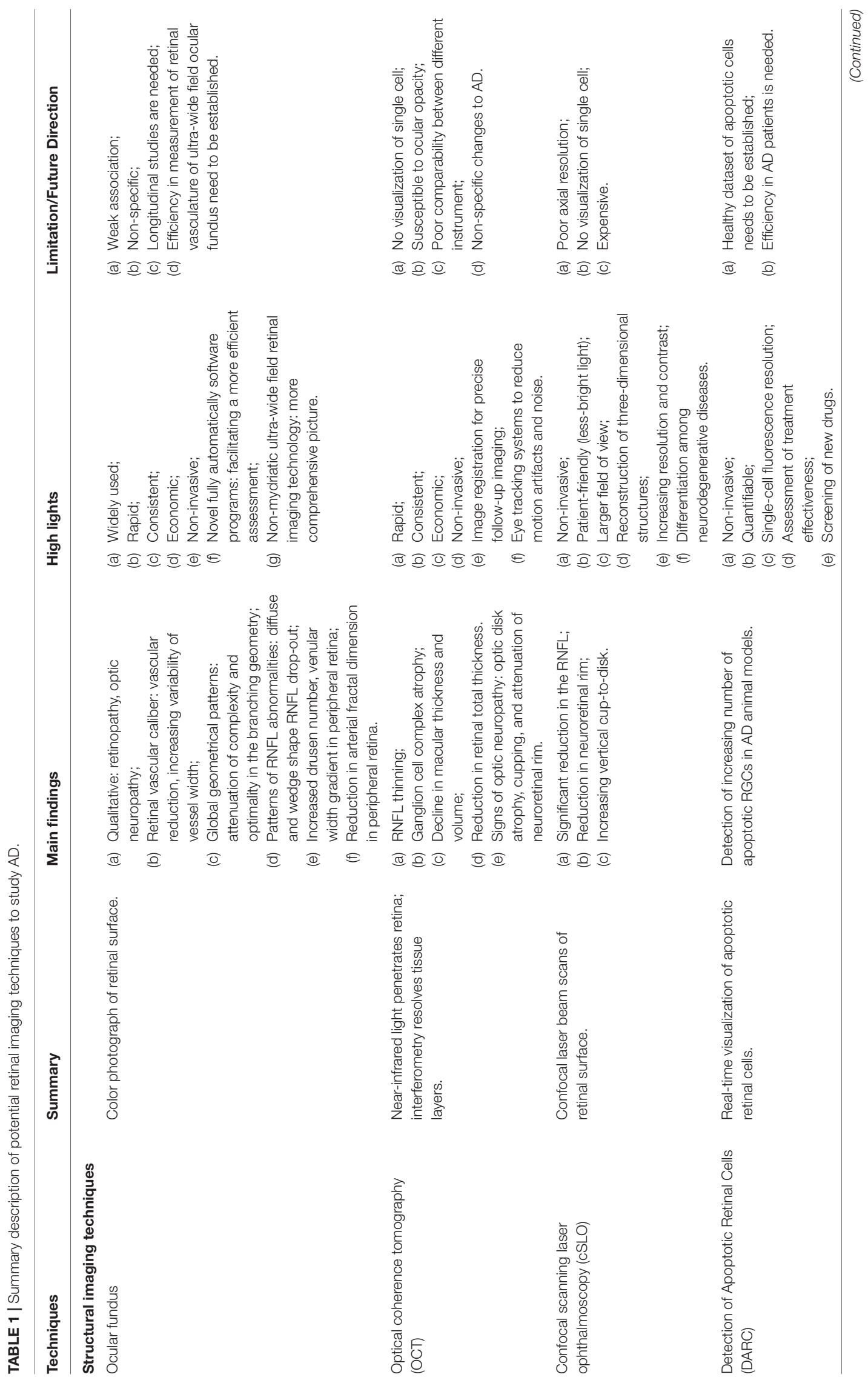



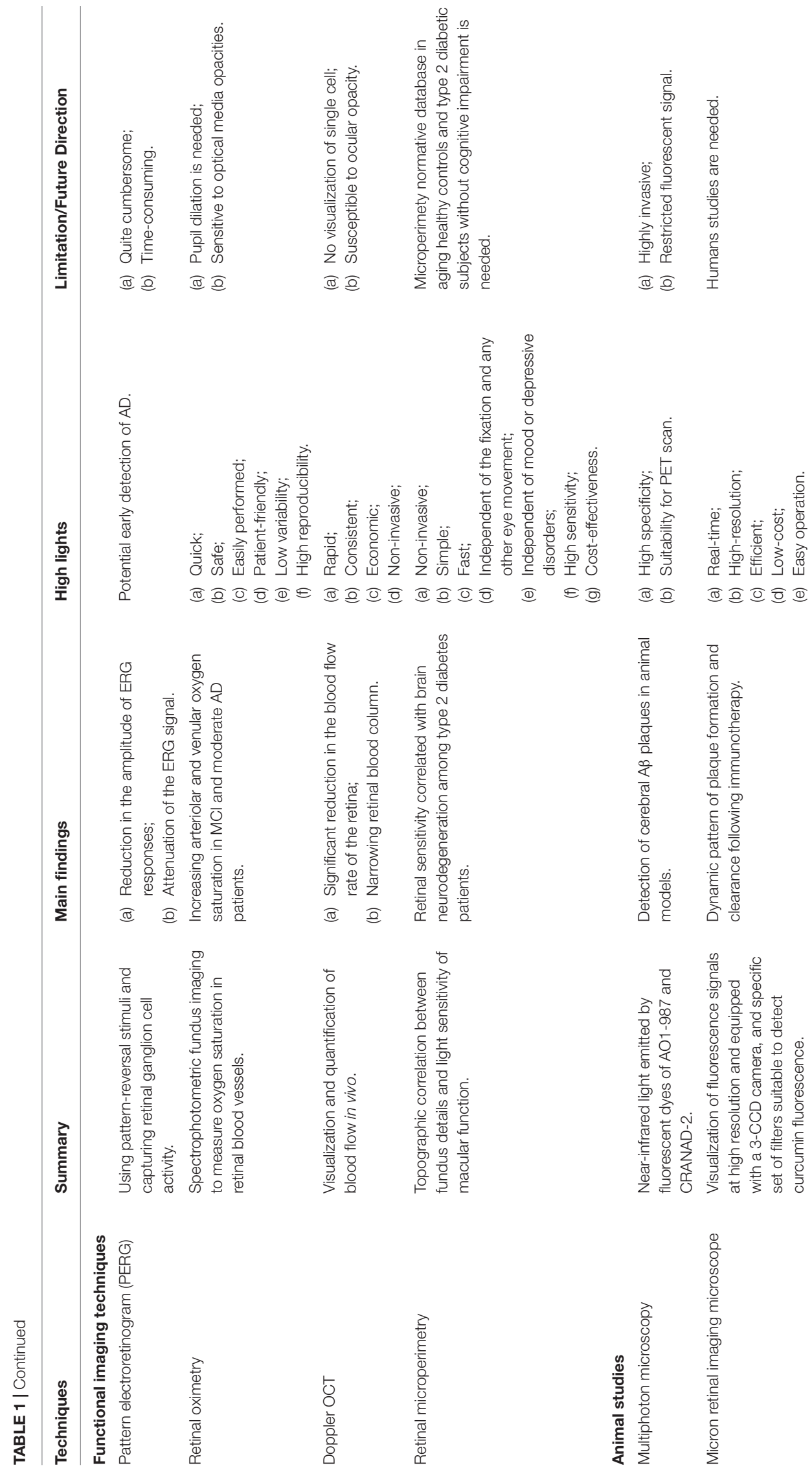


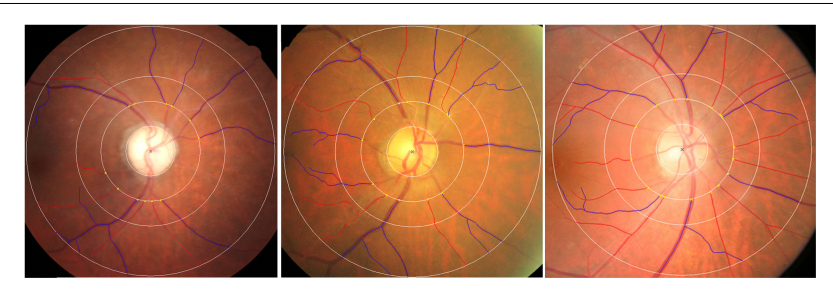

FIGURE 1 | Examples of (left) reduced retinal vascular fractal dimension, (middle) attenuation retinal venular caliber and increased retinal vascular tortuosity in AD patients, (right) normal retinal fundus photograph. Red: arterioles; blue: venules. The measured area of retinal vascular parameters was standardized as the region from 0.5 to 2.0 disk diameters away from the disk margin Cheung et al. (2014).

2001; Iseri et al., 2006; Berisha et al., 2007; Kesler et al., 2011; Kang and Kim, 2013; Marziani et al., 2013; Ascaso et al., 2014; Polo et al., 2014; Gunes et al., 2015) and inferior quadrants (Parisi et al., 2001; Iseri et al., 2006; Kesler et al., 2011; Marziani et al., 2013; Ascaso et al., 2014; Polo et al., 2014; Gunes et al., 2015) (Figure 3). The retinal total thickness reduction in AD patients was also verified by different commercially available OCT devices (Marziani et al., 2013). Additionally to the defects in the RNFL and total retinal thickness, reduction of total macular volume was also observed in $\mathrm{AD}$ patients and related to the severity of the disease based on the MMSE (Iseri et al., 2006; Moreno-Ramos et al., 2013). There are, however, other studies having conflicting findings with the results described above (Paquet et al., 2007; Kesler et al., 2011; Kirbas et al., 2013; Kromer et al., 2013, 2014). With respect to the optic nerve analyzer, AD patients were more likely to show signs of optic neuropathy, such as optic disk atrophy, pathology optic disk cupping, and attenuation of the neuroretinal rim, when compared with age-matched healthy subjects (Tsai et al., 1991; Hedges et al., 1996).

More recently, OCT has evolved from older generations of TD-OCT to SD-OCT, which can capture 3D volume of retina with a higher scan speed, higher axial resolution and lower measurement variability (Leung et al., 2009). With this advance in OCT technology, precise evaluation of the sublayers of RGC is now available and moreover can be assessed using OCT automated segmentation algorithms (Schuman et al., 2009). The GC-IPL, ganglion cell layer and photoreceptor layer can be visualized using SD-OCT. This may provide additional insights into the pathology of neurodegenerative conditions. Changes in the macular GC-IPL and, macular ganglion cell complex (includes RNFL, ganglion cell layer and IPL) and photoreceptor layer are more sensitive reflections of neurodegenerative disease than the peripapillary RNFL reduction (Tan et al., 2009; Mwanza et al., 2012), since macular is the area with greatest density of cone photoreceptors cells and RGCs. Therefore, several recent studies have reported changes of specific retinal layers at the macular region in $\mathrm{AD}$ and supported the macular GC-IPL thinning being a new marker for detection of neurodegenerative damage in early AD and MCI (Gharbiya et al., 2014; Bayhan et al., 2015; Cheung et al., 2015; Gao et al., 2015). Two recent studies using

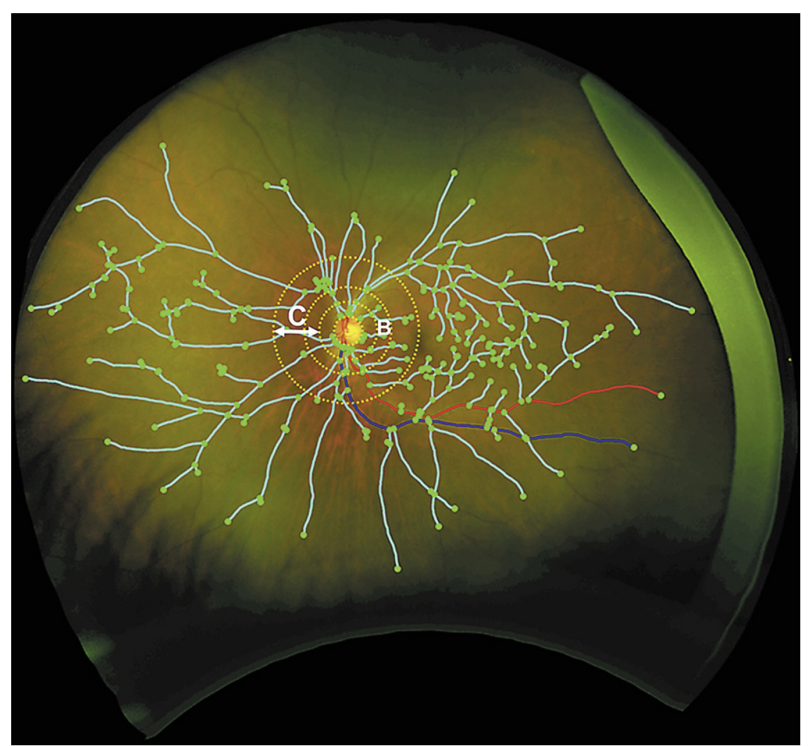

FIGURE 2 | Grading of vascular parameters on ultra-wide field imaging. Dashed circles represent grading zone B: 0.5-1 OD diameter. C: 1-2 OD diameter. Turquoise lines: vascular fractal dimension; green dots: branching points; red line: arteriole; blue: venule (Csincsik et al., 2018).

the improved OCT indicated significant reductions in macular GCC in AD patients than the age-matched healthy controls (Marziani et al., 2013; Bayhan et al., 2015). When compared to patients with periperpillary RNFL axonal loss, patients with MCI were more specifically present with reduced macular GC-IPL (Cheung et al., 2015). The first prospective and longitudinal study found the attenuation of macular RNFL might be the earliest anatomic marker of retinal neuronal loss in the preclinical stage of $\mathrm{AD}$ and such loss accounted for approximate $10 \%$ of the variance in neocortical amyloidosis observed by PET imaging (Santos et al., 2018).

Limitations of these technologies should be noted when interpreting the potential utility of OCT in AD management. First, ocular opacity, such as cataract, has profound impacts on the quality of the imaging. However, newer imaging methods, such as Swept source (SS)-OCT, could overcome this limiting factor, since SS-OCT offers additional advantages over SDOCT in penetration depth and therefore reduced sensitivity to ocular opacity (Esmaeelpour et al., 2010). Second, instrument variability and different protocols in studies may hinder the comparability between different studies. It should be noted that meta analysis of the different commercial OCT results might be offset to statistical differences in the retinal structural changes. Therefore, standardized OCT protocol to study AD is needed in the near future. Third, structural changes in retina observed in $\mathrm{AD}$ patients may be non-specific to $\mathrm{AD}$ and shared by other ocular diseases, such as decreased RNFL in glaucoma. Nevertheless, combination OCT measurements of structural changes in retina and other biomarkers could potentially be a valuable approach in $\mathrm{AD}$ diagnosis and prognostication. 


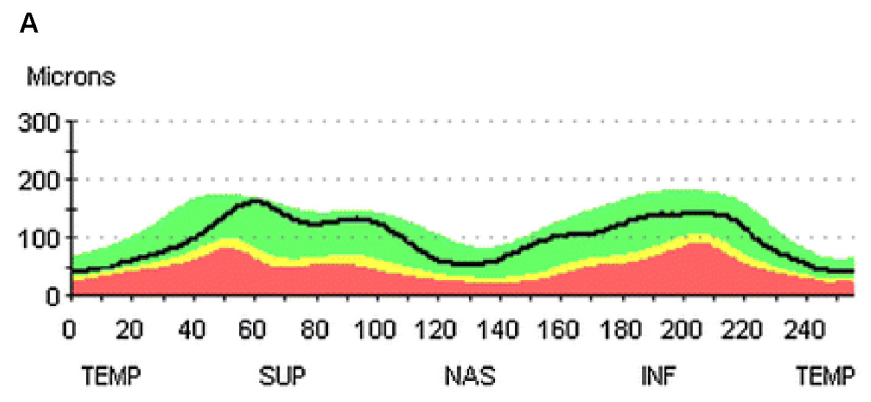

B

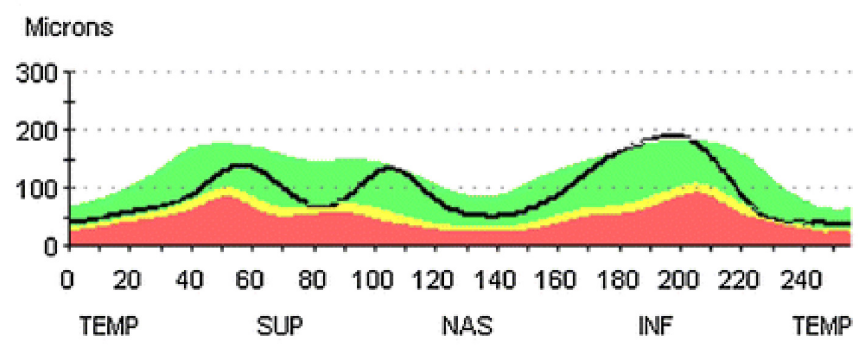

C

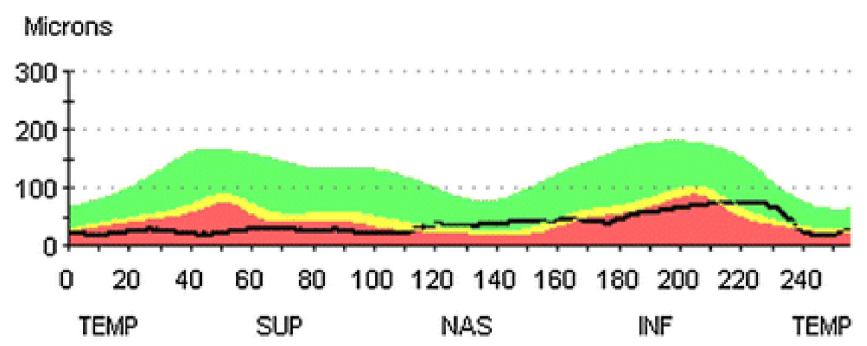

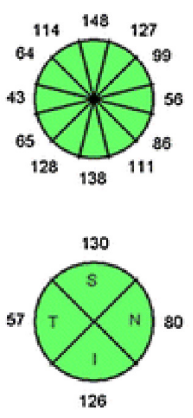
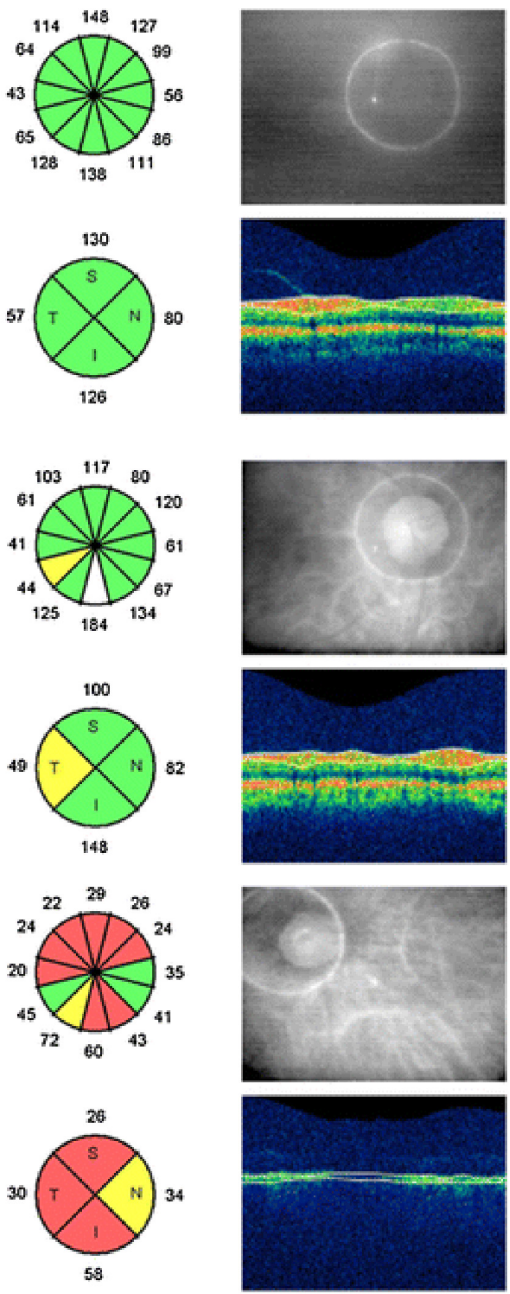

FIGURE 3 | Example of peripapillary retinal nerve fiber layer (RNFL) thickness OCT measurements taken from the right eye of: a healthy control with all quadrants with (A) thickness normal for age, (B) a MCl patient with a decreased RFNL thickness in the temporal quadrant, and (C) a AD patient with decreased RFNL thickness in all quadrants. The line of graphic shows the RFNL thickness of the scanning circle as seen around the optic nerve head in the picture on the right. The colors represent normal distribution percentiles for age. Green: 95-5\%; yellow: 5-1\%; red: 1-0\% (Ascaso et al., 2014).

\section{Confocal Scanning Laser Ophthalmoscopy (cSLO)}

Confocal scanning laser ophthalmoscopy is an imaging technique and allows for reconstructing three-dimensional structures with advantages of increasing resolution and contrast. Morphological changes in the $\mathrm{ONH}$ measured by cSLO, including a significant reduction in the RNFL, neuroretinal rim, and increased vertical cup-to-disk, were found in $\mathrm{AD}$ patients in comparison to healthy subjects (Danesh-Meyer et al., 2006). In contrast to this finding, a recent study using cSLO did not document significant difference in the $\mathrm{ONH}$ between $\mathrm{AD}$ patients and healthy controls (Kurna et al., 2014). However, AD patients could be differentiated from glaucoma patients, implying the potential utility of cSLO as a new biomarker to recognize specific neurodegenerative diseases (Kurna et al., 2014). Using a lipid curcumin fluorochome and a modified point cSLO, a recent study reported the increased burden of retinal amyloid deposits in live AD patients, which might lead to a practical approach for large-scale AD screening and monitoring (Koronyo et al., 2017).

\section{Detection of Apoptotic Retinal Cells (DARC)}

Detection of apoptotic retinal cells is a novel imaging technology that can monitor RGC apoptosis. Although RGCs can not be real-time visualized without a marker, it has been indicated that DARC is a useful tool to detect RGC apoptosis in vivo in experimental animal models (Cordeiro et al., 2004, 2010; Guo et al., 2006, 2007; Maass et al., 2007) (Figure 4). Combined with fluorescein labeled annexin $\mathrm{V}$ and a cSLO, DARC allows for visualization of single RGCs undergoing apoptosis. Using DARC imaging, the number of apoptotic RGCs in a AD model significantly increased, which became even worse under oxidative 


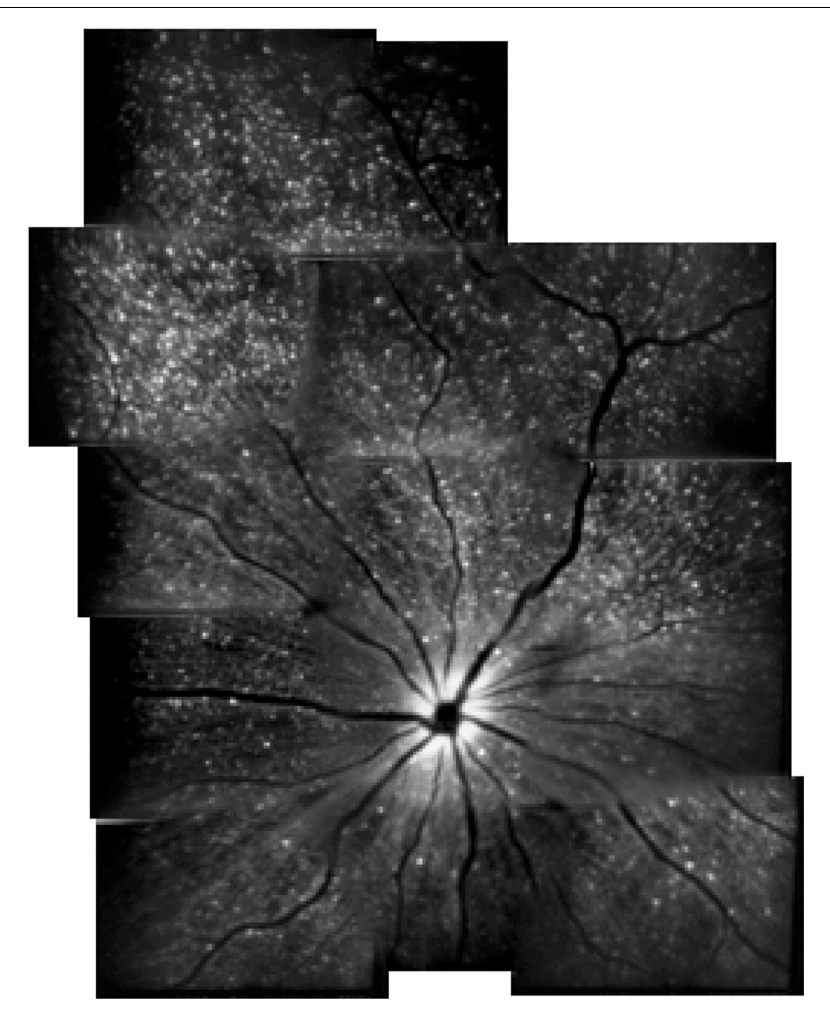

FIGURE 4 | Example of detection of apoptotic retinal cells (DARC) in a rat model (Cordeiro et al., 2004).

stress when compared to healthy controls (Cordeiro et al., 2010). Furthermore, intraocular administration of extraneous $\mathrm{A} \beta$ peptides can lead to considerable RGC apoptosis in vivo, which can be treated and reserved by drugs targeting $A \beta$ pathway (Guo et al., 2007). This finding promises the potential of assessing treatment effectiveness and screening new drugs by the means of DARC (Guo et al., 2006, 2007, 2014; Salt et al., 2014). Accordingly, although there is no study investigating the efficacy of DARC in patients with $\mathrm{AD}$, a Phase I clinical trial of using DARC (ISRCTN59484478) in healthy and glaucoma subjects has recently been completed and DARC is believed to be used as a valuable tool in early diagnosis and treatment assessment for AD.

\section{FUNCTIONAL IMAGING METHODS}

\section{Pattern Electroretinogram (PERG)}

Pattern electroretinogram allows to objectively assess ganglion cells and their axons' electrical response to patterned stimuli (Mafei and Fiorentini, 1981; Katz et al., 1989; Trick et al., 1989). Several studies have consistently reported abnormal PERG in $\mathrm{AD}$ patients, such as a significant reduction in the amplitude of ERG responses and an attenuation of the ERG signal (Katz et al., 1989; Trick et al., 1989; Parisi et al., 2001), further suggesting the evidence of retinal ganglion cell dysfunction related to the structural changes in the RNFL of AD patients (Parisi et al., 2001; Parisi, 2003). However, conflicting results were also demonstrated in other studies revealing normal ERG responses in mild to moderate AD (Strenn et al., 1991; Kergoat et al., 2002). Nevertheless, PERG can be useful in early phase of the AD, when RGC dysfunction and optic nerve alteration are already existed (Krasodomska et al., 2010) (Figure 5). However, PERG is quite cumbersome and time-consuming, which may limit its broad availability and utility.

\section{Retinal Oximetry}

Retinal oximetry is a spectrophotometric fundus imaging to measure oxygen saturation in retinal blood vessels in a non-invasive, fast and safe manner(Jani et al., 2014). Retinal oximetry can reliably and repeatedly detect changes in oxygen metabolism to reflect metabolic and functional changes in retina (Yip et al., 2014). Due to the availability of the retinal oximetry to clinical researchers in the past decade, retinal oximetry has offered new insights into several retinal diseases, such as diabetic retinopathy, glaucoma, as well as diseases of the brain, including AD (Stefansson et al., 2017). Einarsdottir et al. (2016) were the first to report oximetry abnormalities in retinas of $\mathrm{AD}$ patients compared with a healthy cohort. These findings have recently been confirmed and extended to patients with MCI (Olafsdottir et al., 2018) (Figure 6). Further studies are needed to confirm and expand the utility of retinal oximetry in $\mathrm{AD}$ clinical practice and trials.

\section{Doppler OCT}

As one of the functional extensions of OCT, Doppler OCT aims to visualize and quantify blood flow in vivo. Significant reduction in the blood flow rate of the retina and narrowing retinal blood column had been identified through Doppler OCT in patients with $\mathrm{AD}$ when compared with control subjects (Berisha et al., 2007), verifying the potential association between changes of blood flow in the retina and the brain. The decreased perfusion both in the retina and the brain may affect ATP synthesis

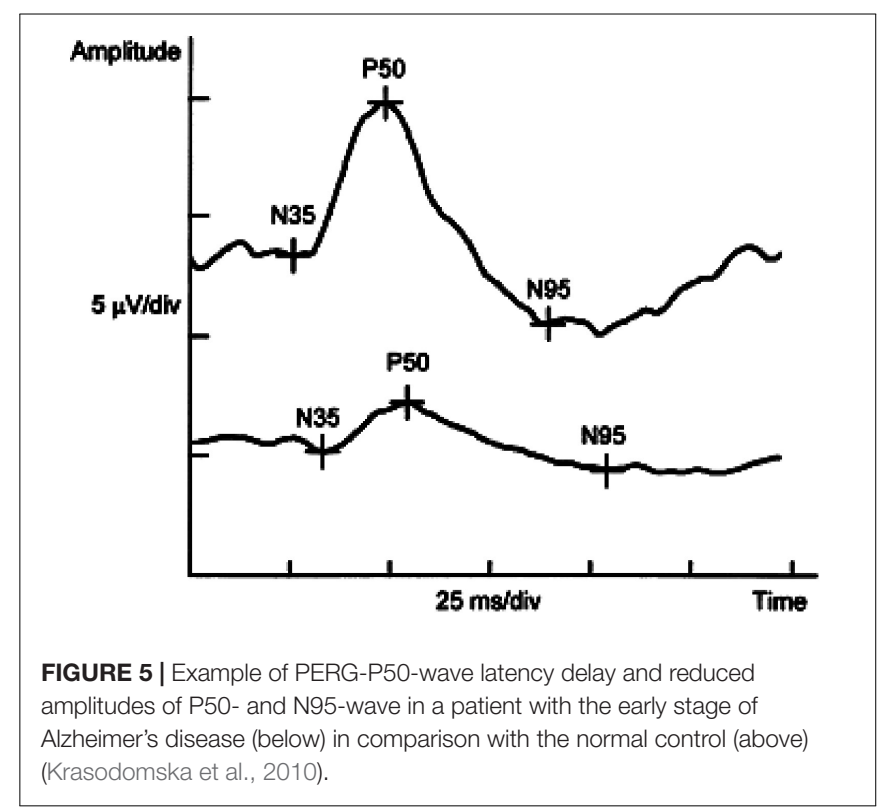




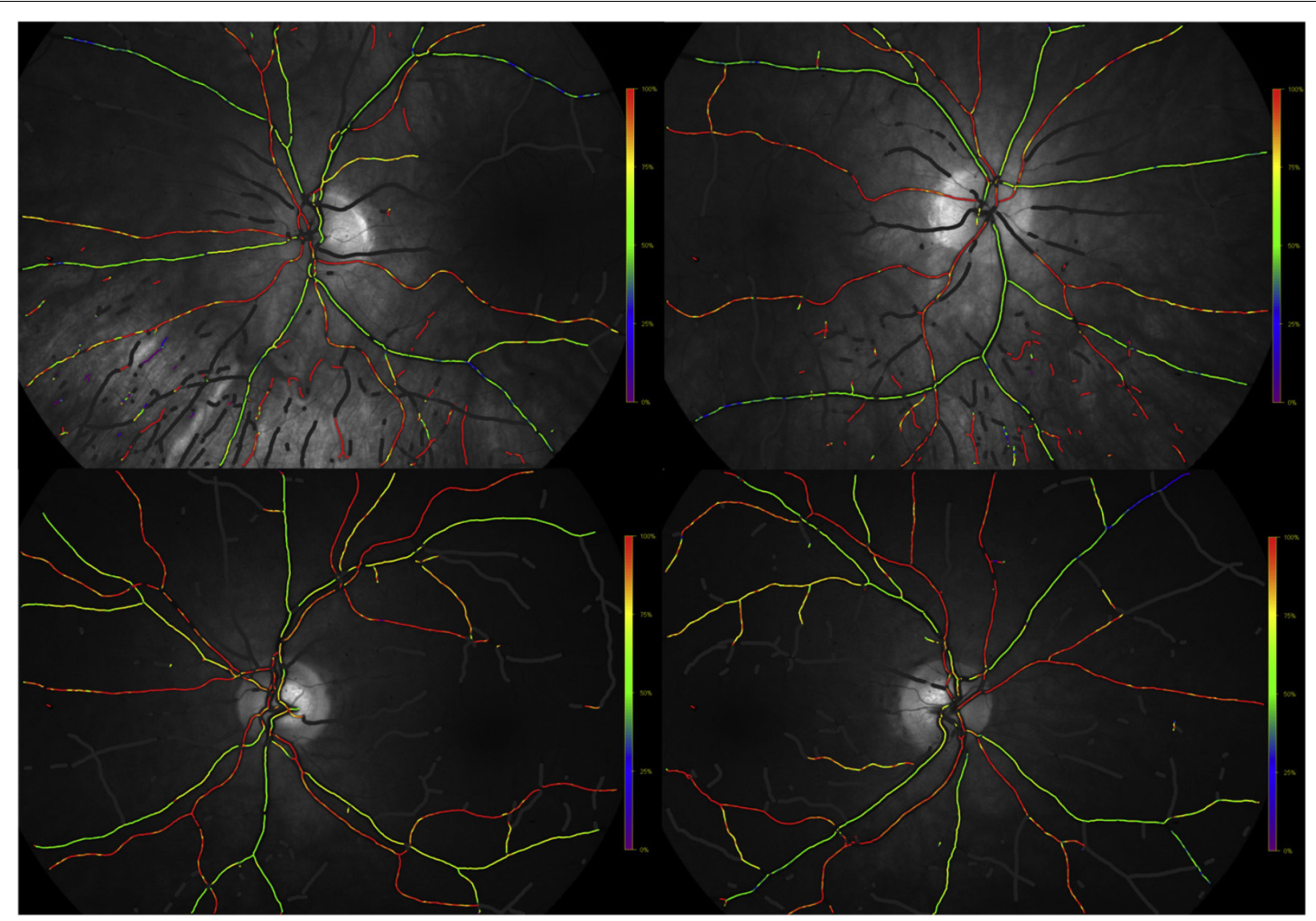

FIGURE 6 | Example of fundus oximetry images from (above) a age-adjusted healthy individual and (below) an mild cognitive impairment patient (Olafsdottir et al., 2018).

and cause oxidative stress, which resulted in neuronal death (Ruitenberg et al., 2005). Doppler OCT has been shown the potential to improve the ability to diagnose and monitor $\mathrm{AD}$ through ocular vascular changes.

\section{Retinal Microperimetry}

Retinal microperimetry is a simple, non-invasive and fast test that measures the topographic correlation between fundus details and light sensitivity for macular function (Rohrschneider et al., 2008; Acton and Greenstein, 2013) (Figure 7). Independent of the fixation and any other eye movement, retinal microperimetry is a strong candidate examination for monitoring $\mathrm{AD}$. It has been indicated that retinal sensitivity evaluated by retinal microperimetry correlated with brain neurodegeneration and could be a novel biomarker for predicting the risk of developing $\mathrm{AD}$ among type 2 diabetes patients (Ciudin et al., 2017). Some recent studies have documented more sensitivity of microperimetry in identifying early functional changes of the retina than ERG ( $\mathrm{Wu}$ et al., 2014). Therefore, retinal microperimetry might be a cost effective way of managing the diagnosis and progression of $\mathrm{AD}$ in the future.

\section{STUDIES IN ANIMAL MODELS}

Some of the promising retinal imaging technologies have been applied and tested in animal models. In a mice model expressing human mutant P301S tau, aggregation and progression of fibrillar tau in the retina were detected by cSLO over several months (Schon et al., 2012). This technique may be suitable to manage therapeutic interventions aimed at reducing fibrillar tau aggregation in the retina. Using fluorescent dyes AO1-987 and CRANAD-2 which can emit near-infrared light, multiphoton microscopy has been used to detect cerebral $A \beta$ plaques in AD animal models (Hintersteiner et al., 2005). Despite of high specificity and suitability in PET scan (Ran et al., 2009), this technique is highly invasive and a cranial window is needed (Dong et al., 2010). Moreover, fluorescent signal is limited on the cortical surface (Meyer-Luehmann et al., 2008). Micron II retinal imaging microscope was used in vivo to document dynamic pattern of plaque formation and clearance following immunotherapy (Koronyo et al., 2017). This technology may be a useful tool to monitor progression and assess therapy efficiency in $\mathrm{AD}$ patients.

\section{FUTURE DIRECTIONS}

Even though the current findings and applications of retinal imaging in $\mathrm{AD}$ patients offer a promising future, however, there are still several gaps to be filled in the future research. First, the underlying mechanisms between retinal changes and $\mathrm{AD}$ have not been completely elucidated, which may hinder the translation of retinal imaging into a valuable tool in $\mathrm{AD}$ clinical 


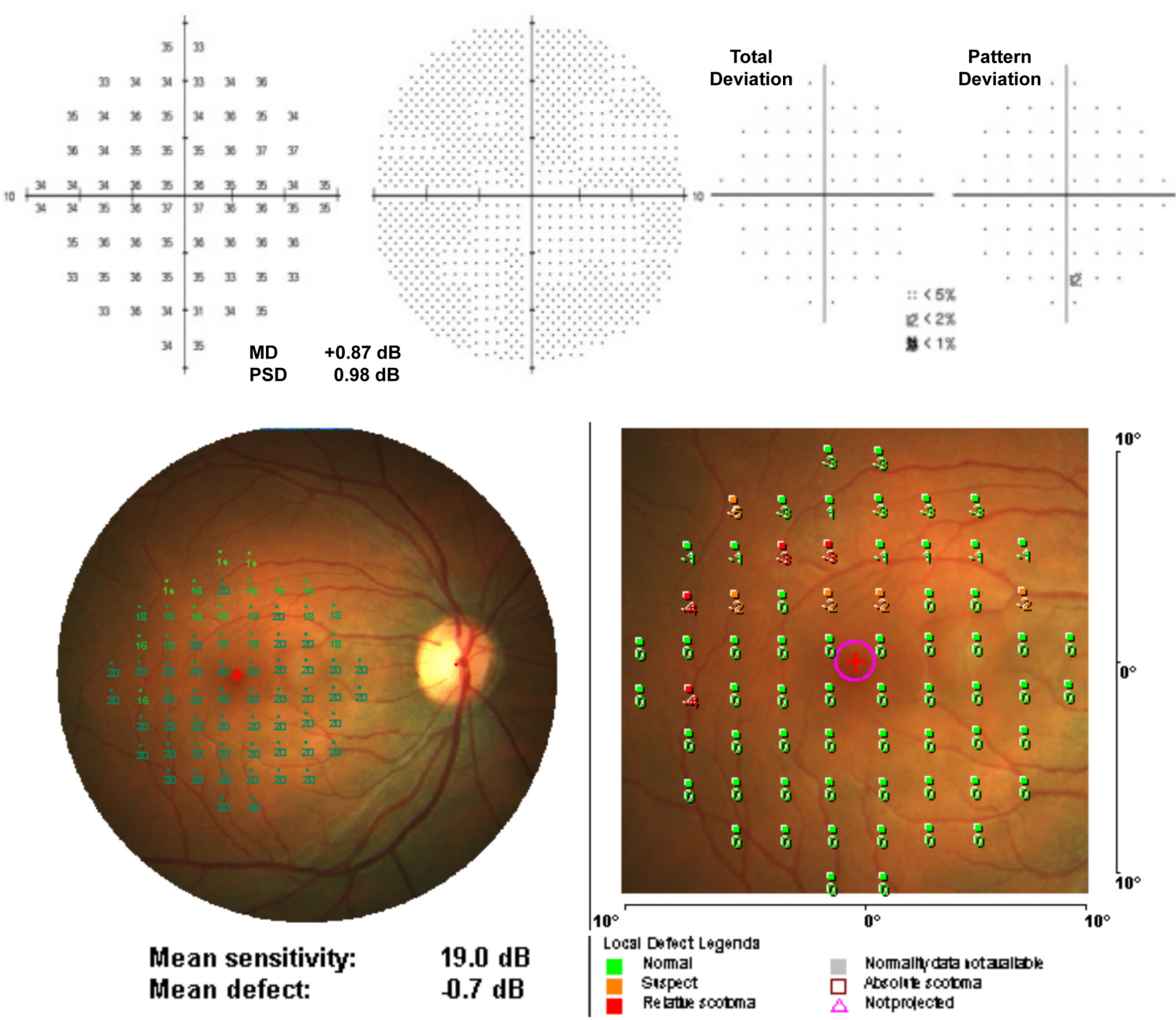

FIGURE 7 | Example of a normal individual measurement from (above) Humphrey Field Analyzer (10-2 pattern, SITA Standard) and (below) MP-1 microperimetry (10-2 pattern, 4-2 strategy) (Acton et al., 2013).

practice. Future experimental research that explores the etiology of $\mathrm{AD}$ and biological mechanism between retinal changes and $\mathrm{AD}$ is needed to facilitate the utility of retinal imaging in $\mathrm{AD}$ patients. Second, studies with large sample size and long-term follow-up are needed to clarify longitudinal retinal changes and its relation to $\mathrm{AD}$, thus building prediction models to identify the patients at risk of developing $\mathrm{AD}$. Third, a large number of novel retinal imaging technologies have been used to estimate the structure and functions of the retina, such as OCT-angiography, and retinal function imager. Very recent work has used OCT-angiography in $\mathrm{AD}$ patients and provided promising results that significant decreased retinal vascular density and enlarged foveal avascular zone were observed in $\mathrm{AD}$ group compared with the control group (Bulut et al., 2018). Further studies are needed to confirm the utility and assess the cost-effectiveness of such newer technologies in $\mathrm{AD}$ monitoring. Furthermore, the diagnostic and prognostic values of combining different retinal imaging technologies with neurological examinations should be investigated for the further development of multimodel for clinical use. Finally, inclusion of different types of dementia, such as Lewy body dementia, to the clinical trial is important to clarify the specific clinical implications of retinal imaging technologies in $\mathrm{AD}$ patients. In addition, some neurodegenerative brain disorders, such as Parkinson's disease, have also shown morphological evidence of disruption of retinal structure and function (Archibald et al., 2009). Understanding neurodegeneration in the retina may provide not only a clearer picture of brain disorders' onset and progression, but also promising non-invasive tools for large-scale screening and monitoring brain diseases.

\section{CONCLUSION}

Structural and functional retinal changes have been suggested as the window to the neurodegenerative diseases. Retinal imaging is a non-invasive, cost-effective and highly promising method to study AD and provides new and additional important insights 
into AD. Future studies investigating underlying mechanisms between retinal changes and $\mathrm{AD}$ and the utility of combining retinal imaging technologies with neurological examinations are needed before retina imaging can be translated as a useful tool in clinical practice.

\section{AUTHOR CONTRIBUTIONS}

HL, ZZ, and YP conceived of the idea for the study. HL and ZZ searched and reviewed literature, drafted and revised the

\section{REFERENCES}

Abramoff, M. D., Lou, Y., Erginay, A., Clarida, W., Amelon, R., Folk, J. C., et al. (2016). Improved automated detection of diabetic retinopathy on a publicly available dataset through integration of deep learning. Invest. Ophthalmol. Vis. Sci. 57, 5200-5206. doi: 10.1167/iovs.16-19964

Acton, J. H., and Greenstein, V. C. (2013). Fundus-driven perimetry (microperimetry) compared to conventional static automated perimetry: similarities, differences, and clinical applications. Can. J. Ophthalmol. 48, 358-363. doi: 10.1016/j.jcjo.2013.03.021

Archibald, N. K., Clarke, M. P., Mosimann, U. P., and Burn, D. J. (2009). The retina in Parkinson's disease. Brain 132(Pt 5), 1128-1145. doi: 10.1093/brain/ awp068

Ascaso, F. J., Cruz, N., Modrego, P. J., Lopez-Anton, R., Santabarbara, J., Pascual, L. F., et al. (2014). Retinal alterations in mild cognitive impairment and Alzheimer's disease: an optical coherence tomography study. J. Neurol. 261, 1522-1530. doi: 10.1007/s00415-014-7374-z

Baker, M. L., Marino Larsen, E. K., Kuller, L. H., Klein, R., Klein, B. E., Siscovick, D. S., et al. (2007). Retinal microvascular signs, cognitive function, and dementia in older persons: the cardiovascular health study. Stroke 38, 2041-2047. doi: 10.1161/STROKEAHA.107.483586

Bateman, R. J., Xiong, C., Benzinger, T. L., Fagan, A. M., Goate, A., Fox, N. C., et al. (2012). Clinical and biomarker changes in dominantly inherited Alzheimer's disease. N. Engl. J. Med. 367, 795-804. doi: 10.1056/NEJMoa1202753

Bayhan, H. A., Aslan Bayhan, S., Celikbilek, A., Tanik, N., and Gurdal, C. (2015). Evaluation of the chorioretinal thickness changes in Alzheimer's disease using spectral-domain optical coherence tomography. Clin. Exp. Ophthalmol. 43, 145-151. doi: 10.1111/ceo.12386

Beckett, L. A., Harvey, D. J., Gamst, A., Donohue, M., Kornak, J., Zhang, H. et al. (2010). The Alzheimer's disease neuroimaging initiative: annual change in biomarkers and clinical outcomes. Alzheimers Dement. 6, 257-264. doi: 10.1016/j.jalz.2010.03.002

Berisha, F., Feke, G. T., Trempe, C. L., McMeel, J. W., and Schepens, C. L. (2007). Retinal abnormalities in early Alzheimer's disease. Invest. Ophthalmol. Vis. Sci. 48, 2285-2289. doi: 10.1167/iovs.06-1029

Brookmeyer, R., Gray, S., and Kawas, C. (1998). Projections of Alzheimer's disease in the United States and the public health impact of delaying disease onset. Am. J. Public Health 88, 1337-1342. doi: 10.2105/AJPH.88.9.1337

Brookmeyer, R., Johnson, E., Ziegler-Graham, K., and Arrighi, H. M. (2007). Forecasting the global burden of Alzheimer's disease. Alzheimers Dement. 3, 186-191. doi: 10.1016/j.jalz.2007.04.381

Bruban, J., Glotin, A. L., Dinet, V., Chalour, N., Sennlaub, F., Jonet, L., et al. (2009). Amyloid-beta(1-42) alters structure and function of retinal pigmented epithelial cells. Aging Cell 8, 162-177. doi: 10.1111/j.1474-9726.2009.00456.x

Bull, N. D., Guidi, A., Goedert, M., Martin, K. R., and Spillantini, M. G. (2012). Reduced axonal transport and increased excitotoxic retinal ganglion cell degeneration in mice transgenic for human mutant P301S tau. PLoS One 7:e34724. doi: 10.1371/journal.pone.0034724

Bulut, M., Kurtulus, F., Gozkaya, O., Erol, M. K., Cengiz, A., Akidan, M., et al. (2018). Evaluation of optical coherence tomography angiographic findings in Alzheimer's type dementia. Br. J. Ophthalmol. 102, 233-237. doi: 10.1136/ bjophthalmol-2017-310476

Cai, J., Qi, X., Kociok, N., Skosyrski, S., Emilio, A., Ruan, Q., et al. (2012). betaSecretase (BACE1) inhibition causes retinal pathology by vascular dysregulation manuscript. YP reviewed and edited the manuscript. All authors read and approved the final manuscript.

\section{FUNDING}

This work was supported by the Key Project of Product, Study and Research of Guangzhou city (No. 201508020058) to YP, the International Collaboration Program of Universities in Guangdong Province (No. 2012gjhz001) to YP.

and accumulation of age pigment. EMBO Mol. Med. 4, 980-991. doi: 10.1002/ emmm.201101084

Cavallari, M., Stamile, C., Umeton, R., Calimeri, F., and Orzi, F. (2015). Novel method for automated analysis of retinal images: results in subjects with hypertensive retinopathy and CADASIL. Biomed Res. Int. 2015:752957. doi: 10.1155/2015/752957

Cheung, C. Y., Ikram, M. K., Sabanayagam, C., and Wong, T. Y. (2012a). Retinal microvasculature as a model to study the manifestations of hypertension. Hypertension 60, 1094-1103. doi: 10.1161/HYPERTENSIONAHA.111.189142

Cheung, C. Y., Ong, Y. T., Hilal, S., Ikram, M. K., Low, S., Ong, Y. L., et al. (2015). Retinal ganglion cell analysis using high-definition optical coherence tomography in patients with mild cognitive impairment and Alzheimer's disease. J. Alzheimers Dis. 45, 45-56. doi: 10.3233/JAD- 141659

Cheung, C. Y., Ong, Y. T., Ikram, M. K., Ong, S. Y., Li, X., Hilal, S., et al. (2014). Microvascular network alterations in the retina of patients with Alzheimer's disease. Alzheimers Dement. 10, 135-142. doi: 10.1016/j.jalz.2013.06.009

Cheung, C. Y., Thomas, G. N., Tay, W., Ikram, M. K., Hsu, W., Lee, M. L., et al. (2012b). Retinal vascular fractal dimension and its relationship with cardiovascular and ocular risk factors. Am. J. Ophthalmol. 154, 663.e1-674.e1. doi: 10.1016/j.ajo.2012.04.016

Cheung, N., Mosley, T., Islam, A., Kawasaki, R., Sharrett, A. R., Klein, R., et al. (2010). Retinal microvascular abnormalities and subclinical magnetic resonance imaging brain infarct: a prospective study. Brain 133( $\mathrm{Pt} 7)$, 1987-1993. doi: 10.1093/brain/awq127

Cheung, N., and Wong, T. Y. (2012). Predicting risk of diabetic retinopathy from retinal vessel analysis: personalized medicine in transition. Arch. Ophthalmol. 130, 783-784. doi: 10.1001/archophthalmol.2012.727

Ciudin, A., Simo-Servat, O., Hernandez, C., Arcos, G., Diego, S., Sanabria, A., et al. (2017). Retinal microperimetry: a new tool for identifying patients with type 2 diabetes at risk for developing Alzheimer disease. Diabetes Metab. Res. Rev. 66, 3098-3104. doi: 10.2337/db17-0382

Coppola, G., Di Renzo, A., Ziccardi, L., Martelli, F., Fadda, A., Manni, G., et al. (2015). Optical coherence tomography in Alzheimer's disease: a meta-analysis. PLoS One 10:e0134750. doi: 10.1371/journal.pone.0134750

Cordeiro, M. F., Guo, L., Coxon, K. M., Duggan, J., Nizari, S., Normando, E. M., et al. (2010). Imaging multiple phases of neurodegeneration: a novel approach to assessing cell death in vivo. Cell Death Dis. 1:e3. doi: 10.1038/cddis.2009.3

Cordeiro, M. F., Guo, L., Luong, V., Harding, G., Wang, W., Jones, H. E., et al. (2004). Real-time imaging of single nerve cell apoptosis in retinal neurodegeneration. Proc. Natl. Acad. Sci. U.S.A. 101, 13352-13356. doi: 10. 1073/pnas.0405479101

Crowe, M. J., Bresnahan, J. C., Shuman, S. L., Masters, J. N., and Beattie, M. S. (1997). Apoptosis and delayed degeneration after spinal cord injury in rats and monkeys. Nat. Med. 3, 73-76. doi: 10.1038/nm0197-73

Csincsik, L., MacGillivray, T. J., Flynn, E., Pellegrini, E., Papanastasiou, G., Barzegar-Befroei, N., et al. (2018). Peripheral retinal imaging biomarkers for Alzheimer's disease: a pilot study. Ophthalmic Res. 59, 182-192. doi: 10.1159/ 000487053

Danesh-Meyer, H. V., Birch, H., Ku, J. Y., Carroll, S., and Gamble, G. (2006). Reduction of optic nerve fibers in patients with Alzheimer disease identified by laser imaging. Neurology 67, 1852-1854. doi: 10.1212/01.wnl.0000244490. $07925.8 \mathrm{~b}$

Dinet, V., Bruban, J., Chalour, N., Maoui, A., An, N., Jonet, L., et al. (2012). Distinct effects of inflammation on gliosis, osmohomeostasis, and vascular integrity 
during amyloid beta-induced retinal degeneration. Aging Cell 11, 683-693. doi: $10.1111 / j .1474-9726.2012 .00834 . x$

Ding, J., Strachan, M. W., Fowkes, F. G., Wong, T. Y., Macgillivray, T. J., Patton, N., et al. (2011). Association of retinal arteriolar dilatation with lower verbal memory: the Edinburgh type 2 diabetes study. Diabetologia 54, 1653-1662. doi: 10.1007/s00125-011-2129-1

Dong, J., Revilla-Sanchez, R., Moss, S., and Haydon, P. G. (2010). Multiphoton in vivo imaging of amyloid in animal models of Alzheimer's disease. Neuropharmacology 59, 268-275. doi: 10.1016/j.neuropharm.2010.04.007

Doody, R. S., Thomas, R. G., Farlow, M., Iwatsubo, T., Vellas, B., Joffe, S., et al. (2014). Phase 3 trials of solanezumab for mild-to-moderate Alzheimer's disease. N. Engl. J. Med. 370, 311-321. doi: 10.1056/NEJMoa1312889

Dubois, B., Feldman, H. H., Jacova, C., Hampel, H., Molinuevo, J. L., Blennow, K., et al. (2014). Advancing research diagnostic criteria for Alzheimer's disease: the IWG-2 criteria. Lancet Neurol. 13, 614-629. doi: 10.1016/S1474-4422(14) 70090-0

Dubois, B., Hampel, H., Feldman, H. H., Scheltens, P., Aisen, P., Andrieu, S., et al. (2016). Preclinical Alzheimer's disease: definition, natural history, and diagnostic criteria. Alzheimers Dement. 12, 292-323. doi: 10.1016/j.jalz.2016. 02.002

Einarsdottir, A. B., Hardarson, S. H., Kristjansdottir, J. V., Bragason, D. T., Snaedal, J., and Stefansson, E. (2016). Retinal oximetry imaging in Alzheimer's disease. J. Alzheimers Dis. 49, 79-83. doi: 10.3233/JAD- 150457

Esmaeelpour, M., Povazay, B., Hermann, B., Hofer, B., Kajic, V., Kapoor, K., et al. (2010). Three-dimensional 1060-nm OCT: choroidal thickness maps in normal subjects and improved posterior segment visualization in cataract patients. Invest. Ophthalmol. Vis. Sci. 51, 5260-5266. doi: 10.1167/iovs.105196

Faden, A. I., and Salzman, S. (1992). Pharmacological strategies in CNS trauma. Trends Pharmacol. Sci. 13, 29-35. doi: 10.1016/0165-6147(92)90013-V

Fagan, A. M., Xiong, C., Jasielec, M. S., Bateman, R. J., Goate, A. M., Benzinger, T. L., et al. (2014). Longitudinal change in CSF biomarkers in autosomaldominant Alzheimer's disease. Sci. Transl. Med. 6:226ra230. doi: 10.1126/ scitranslmed.3007901

Feke, G. T., Hyman, B. T., Stern, R. A., and Pasquale, L. R. (2015). Retinal blood flow in mild cognitive impairment and Alzheimer's disease. Alzheimers Dement. 1, 144-151. doi: 10.1016/j.dadm.2015.01.004

Frost, S., Kanagasingam, Y., Sohrabi, H., Vignarajan, J., Bourgeat, P., Salvado, O., et al. (2013). Retinal vascular biomarkers for early detection and monitoring of Alzheimer's disease. Transl. Psychiatry 3:e233. doi: 10.1038/tp.2012.150

Gao, L., Liu, Y., Li, X., Bai, Q., and Liu, P. (2015). Abnormal retinal nerve fiber layer thickness and macula lutea in patients with mild cognitive impairment and Alzheimer's disease. Arch. Gerontol. Geriatr. 60, 162-167. doi: 10.1016/j. archger.2014.10.011

Garcia-Martin, E. S., Rojas, B., Ramirez, A. I., de Hoz, R., Salazar, J. J., Yubero, R., et al. (2014). Macular thickness as a potential biomarker of mild Alzheimer's disease. Ophthalmology 121, 1149.e3-1151.e3. doi: 10.1016/j.ophtha.2013. 12.023

Gasparini, L., Crowther, R. A., Martin, K. R., Berg, N., Coleman, M., Goedert, M., et al. (2011). Tau inclusions in retinal ganglion cells of human P301S tau transgenic mice: effects on axonal viability. Neurobiol. Aging 32, 419-433. doi: 10.1016/j.neurobiolaging.2009.03.002

Gatto, N. M., Varma, R., Torres, M., Wong, T. Y., Johnson, P. L., Segal-Gidan, F., et al. (2012). Retinal microvascular abnormalities and cognitive function in Latino adults in Los Angeles. Ophthalmic Epidemiol. 19, 127-136. doi: 10.3109/ 09286586.2011.615452

Gharbiya, M., Trebbastoni, A., Parisi, F., Manganiello, S., Cruciani, F., D'Antonio, F., et al. (2014). Choroidal thinning as a new finding in Alzheimer's disease: evidence from enhanced depth imaging spectral domain optical coherence tomography. J. Alzheimers Dis. 40, 907-917. doi: 10.3233/JAD132039

Ghiso, J. A., Doudevski, I., Ritch, R., and Rostagno, A. A. (2013). Alzheimer's disease and glaucoma: mechanistic similarities and differences. J. Glaucoma 22(Suppl. 5), S36-S38. doi: 10.1097/IJG.0b013e3182934af6

Golzan, S. M., Goozee, K., Georgevsky, D., Avolio, A., Chatterjee, P., Shen, K., et al. (2017). Retinal vascular and structural changes are associated with amyloid burden in the elderly: ophthalmic biomarkers of preclinical Alzheimer's disease. Alzheimers Res. Ther. 9:13. doi: 10.1186/s13195-017-0239-9
Grundke-Iqbal, I., Iqbal, K., Tung, Y. C., Quinlan, M., Wisniewski, H. M., and Binder, L. I. (1986). Abnormal phosphorylation of the microtubule-associated protein tau (tau) in Alzheimer cytoskeletal pathology. Proc. Natl. Acad. Sci. U.S.A. 83, 4913-4917. doi: 10.1073/pnas.83.13.4913

Gunes, A., Demirci, S., Tok, L., Tok, O., and Demirci, S. (2015). Evaluation of retinal nerve fiber layer thickness in Alzheimer disease using spectral-domain optical coherence tomography. Turk. J. Med. Sci. 45, 1094-1097. doi: 10.3906/ sag-1405-114

Guo, L., Davis, B., Nizari, S., Normando, E. M., Shi, H., Galvao, J., et al. (2014). Direct optic nerve sheath (DONS) application of Schwann cells prolongs retinal ganglion cell survival in vivo. Cell Death Dis. 5:e1460. doi: 10.1038/cddis. 2014.399

Guo, L., Duggan, J., and Cordeiro, M. F. (2010). Alzheimer's disease and retinal neurodegeneration. Curr. Alzheimer Res. 7, 3-14. doi: 10.2174/ 156720510790274491

Guo, L., Salt, T. E., Luong, V., Wood, N., Cheung, W., Maass, A., et al. (2007). Targeting amyloid-beta in glaucoma treatment. Proc. Natl. Acad. Sci. U.S.A. 104, 13444-13449. doi: 10.1073/pnas.0703707104

Guo, L., Salt, T. E., Maass, A., Luong, V., Moss, S. E., Fitzke, F. W., et al. (2006). Assessment of neuroprotective effects of glutamate modulation on glaucomarelated retinal ganglion cell apoptosis in vivo. Invest. Ophthalmol. Vis. Sci. 47, 626-633. doi: 10.1167/iovs.05-0754

Hedges, T. R. III, Perez Galves, R., Speigelman, D., Barbas, N. R., Peli, E., and Yardley, C. J. (1996). Retinal nerve fiber layer abnormalities in Alzheimer's disease. Acta Ophthalmol. Scand. 74, 271-275. doi: 10.1111/j.1600-0420.1996. tb00090.x

Heringa, S. M., Bouvy, W. H., van den Berg, E., Moll, A. C., Kappelle, L. J. and Biessels, G. J. (2013). Associations between retinal microvascular changes and dementia, cognitive functioning, and brain imaging abnormalities: a systematic review. J. Cereb. Blood Flow Metab. 33, 983-995. doi: 10.1038/jcbfm. 2013.58

Hintersteiner, M., Enz, A., Frey, P., Jaton, A. L., Kinzy, W., Kneuer, R., et al. (2005). In vivo detection of amyloid-beta deposits by near-infrared imaging using an oxazine-derivative probe. Nat. Biotechnol. 23, 577-583. doi: 10.1038/nbt1085

Hinton, D. R., Sadun, A. A., Blanks, J. C., and Miller, C. A. (1986). Optic-nerve degeneration in Alzheimer's disease. N. Engl. J. Med. 315, 485-487. doi: 10.1056/ NEJM198608213150804

Ho, W. L., Leung, Y., Tsang, A. W., So, K. F., Chiu, K., and Chang, R. C. (2012). Review: tauopathy in the retina and optic nerve: does it shadow pathological changes in the brain? Mol. Vis. 18, 2700-2710.

Holtzman, D. M., Morris, J. C., and Goate, A. M. (2011). Alzheimer's disease: the challenge of the second century. Sci. Transl. Med. 3:77sr1. doi: 10.1126/ scitranslmed.3002369

Huang, D., Swanson, E. A., Lin, C. P., Schuman, J. S., Stinson, W. G., Chang, W., et al. (1991). Optical coherence tomography. Science 254, 1178-1181. doi: $10.1126 /$ science. 1957169

Iseri, P. K., Altinas, O., Tokay, T., and Yuksel, N. (2006). Relationship between cognitive impairment and retinal morphological and visual functional abnormalities in Alzheimer disease. J. Neuroophthalmol. 26, 18-24. doi: 10. 1097/01.wno.0000204645.56873.26

Jahn, T. R., Makin, O. S., Morris, K. L., Marshall, K. E., Tian, P., Sikorski, P., et al. (2010). The common architecture of cross-beta amyloid. J. Mol. Biol. 395, 717-727. doi: 10.1016/j.jmb.2009.09.039

James, O. G., Doraiswamy, P. M., and Borges-Neto, S. (2015). PET imaging of tau pathology in Alzheimer's disease and tauopathies. Front. Neurol. 6:38. doi: $10.3389 /$ fneur. 2015.00038

Jani, P. D., Mwanza, J. C., Billow, K. B., Waters, A. M., Moyer, S., and Garg, S. (2014). Normative values and predictors of retinal oxygen saturation. Retina 34, 394-401. doi: 10.1097/IAE.0b013e3182979e7b

Jellinger, K. A., and Attems, J. (2015). Challenges of multimorbidity of the aging brain: a critical update. J. Neural Transm. 122, 505-521. doi: 10.1007/s00702014-1288-x

Joshi, V., Agurto, C., VanNess, R., Nemeth, S., Soliz, P., and Barriga, S. (2014). Comprehensive automatic assessment of retinal vascular abnormalities for computer-assisted retinopathy grading. Conf. Proc. IEEE Eng. Med. Biol. Soc. 2014, 6320-6323. doi: 10.1109/EMBC.2014.6945074

Kang, B. H., and Kim, J. I. (2013). Decreased retinal thickness in patients with Alzheimer's disease. J. Korean Neurol. Assoc. 31, 173-177. 
Katz, B., Rimmer, S., Iragui, V., and Katzman, R. (1989). Abnormal pattern electroretinogram in Alzheimer's disease: evidence for retinal ganglion cell degeneration? Ann. Neurol. 26, 221-225. doi: 10.1002/ana.410260207

Kaur, C., Foulds, W. S., and Ling, E. A. (2008). Blood-retinal barrier in hypoxic ischaemic conditions: basic concepts, clinical features and management. Prog. Retin. Eye Res. 27, 622-647. doi: 10.1016/j.preteyeres.2008.09.003

Kergoat, H., Kergoat, M. J., Justino, L., Chertkow, H., Robillard, A., and Bergman, H. (2002). Visual retinocortical function in dementia of the Alzheimer type. Gerontology 48, 197-203. doi: 10.1159/000058350

Kernt, M., Hadi, I., Pinter, F., Seidensticker, F., Hirneiss, C., Haritoglou, C., et al. (2012). Assessment of diabetic retinopathy using nonmydriatic ultra-widefield scanning laser ophthalmoscopy (Optomap) compared with ETDRS 7-field stereo photography. Diabetes Care 35, 2459-2463. doi: 10.2337/dc12-0346

Kesler, A., Vakhapova, V., Korczyn, A. D., Naftaliev, E., and Neudorfer, M. (2011). Retinal thickness in patients with mild cognitive impairment and Alzheimer's disease. Clin. Neurol. Neurosurg. 113, 523-526. doi: 10.1016/j.clineuro.2011. 02.014

Kim, D. H., Newman, A. B., Hajjar, I., Strotmeyer, E. S., Klein, R., Newton, E., et al. (2011). Retinal microvascular signs and functional loss in older persons: the cardiovascular health study. Stroke 42, 1589-1595. doi: 10.1161/STROKEAHA. 110.605261

Kirbas, S., Turkyilmaz, K., Anlar, O., Tufekci, A., and Durmus, M. (2013). Retinal nerve fiber layer thickness in patients with Alzheimer disease. J. Neuroophthalmol. 33, 58-61. doi: 10.1097/WNO.0b013e318267fd5f

Klaver, C. C., Ott, A., Hofman, A., Assink, J. J., Breteler, M. M., and de Jong, P. T. (1999). Is age-related maculopathy associated with Alzheimer's Disease? The Rotterdam study. Am. J. Epidemiol. 150, 963-968. doi: 10.1093/oxfordjournals. aje.a010105

Koronyo, Y., Biggs, D., Barron, E., Boyer, D. S., Pearlman, J. A., Au, W. J., et al. (2017). Retinal amyloid pathology and proof-of-concept imaging trial in Alzheimer's disease. JCI Insight 2:93621. doi: 10.1172/jci.insight.93621

Koronyo, Y., Salumbides, B. C., Black, K. L., and Koronyo-Hamaoui, M. (2012). Alzheimer's disease in the retina: imaging retinal abeta plaques for early diagnosis and therapy assessment. Neurodegener. Dis. 10, 285-293. doi: 10.1159/ 000335154

Koronyo-Hamaoui, M., Koronyo, Y., Ljubimov, A. V., Miller, C. A., Ko, M. K., Black, K. L., et al. (2011). Identification of amyloid plaques in retinas from Alzheimer's patients and noninvasive in vivo optical imaging of retinal plaques in a mouse model. Neuroimage 54(Suppl. 1), S204-S217. doi: 10.1016/j. neuroimage.2010.06.020

Krasodomska, K., Lubinski, W., Potemkowski, A., and Honczarenko, K. (2010). Pattern electroretinogram (PERG) and pattern visual evoked potential (PVEP) in the early stages of Alzheimer's disease. Doc. Ophthalmol. 121, 111-121. doi: 10.1007/s10633-010-9238-x

Kromer, R., Serbecic, N., Hausner, L., Froelich, L., Aboul-Enein, F., and Beutelspacher, S. C. (2014). Detection of retinal nerve fiber layer defects in Alzheimer's disease using SD-OCT. Front. Psychiatry 5:22. doi: 10.3389/fpsyt. 2014.00022

Kromer, R., Serbecic, N., Hausner, L., Froelich, L., and Beutelspacher, S. C. (2013). Comparison of visual evoked potentials and retinal nerve fiber layer thickness in Alzheimer's disease. Front. Neurol. 4:203. doi: 10.3389/fneur.2013.00203

Kurna, S. A., Akar, G., Altun, A., Agirman, Y., Gozke, E., and Sengor, T. (2014). Confocal scanning laser tomography of the optic nerve head on the patients with Alzheimer's disease compared to glaucoma and control. Int. Ophthalmol. 34, 1203-1211. doi: 10.1007/s10792-014-0004-Z

Leung, C. K., Cheung, C. Y., Weinreb, R. N., Qiu, Q., Liu, S., Li, H., et al. (2009). Retinal nerve fiber layer imaging with spectral-domain optical coherence tomography: a variability and diagnostic performance study. Ophthalmology 116, 1257-1263, 1263.e1-1263.e2. doi: 10.1016/j.ophtha.2009.04.013

Levkovitch-Verbin, H., Quigley, H. A., Kerrigan-Baumrind, L. A., D’Anna, S. A., Kerrigan, D., and Pease, M. E. (2001). Optic nerve transection in monkeys may result in secondary degeneration of retinal ganglion cells. Invest. Ophthalmol. Vis. Sci. 42, 975-982.

Levkovitch-Verbin, H., Quigley, H. A., Martin, K. R., Zack, D. J., Pease, M. E., and Valenta, D. F. (2003). A model to study differences between primary and secondary degeneration of retinal ganglion cells in rats by partial optic nerve transection. Invest. Ophthalmol. Vis. Sci. 44, 3388-3393. doi: 10.1167/iovs. 02-0646
Li, L., Luo, J., Chen, D., Tong, J. B., Zeng, L. P., Cao, Y. Q., et al. (2016). BACE1 in the retina: a sensitive biomarker for monitoring early pathological changes in Alzheimer's disease. Neural Regen. Res. 11, 447-453. doi: 10.4103/1673-5374. 179057

Liew, G., Mitchell, P., Wong, T. Y., Lindley, R. I., Cheung, N., Kaushik, S., et al. (2009). Retinal microvascular signs and cognitive impairment. J. Am. Geriatr. Soc. 57, 1892-1896. doi: 10.1111/j.1532-5415.2009.02459.x

Liu, B., Rasool, S., Yang, Z., Glabe, C. G., Schreiber, S. S., Ge, J., et al. (2009). Amyloid-peptide vaccinations reduce $\{$ beta\}-amyloid plaques but exacerbate vascular deposition and inflammation in the retina of Alzheimer's transgenic mice. Am. J. Pathol. 175, 2099-2110. doi: 10.2353/ajpath.2009.090159

London, A., Benhar, I., and Schwartz, M. (2013). The retina as a window to the brain-from eye research to CNS disorders. Nat. Rev. Neurol. 9, 44-53. doi: 10.1038/nrneurol.2012.227

Lu, Y., Li, Z., Zhang, X., Ming, B., Jia, J., Wang, R., et al. (2010). Retinal nerve fiber layer structure abnormalities in early Alzheimer's disease: evidence in optical coherence tomography. Neurosci. Lett. 480, 69-72. doi: 10.1016/j.neulet.2010. 06.006

Maass, A., von Leithner, P. L., Luong, V., Guo, L., Salt, T. E., Fitzke, F. W., et al. (2007). Assessment of rat and mouse RGC apoptosis imaging in vivo with different scanning laser ophthalmoscopes. Curr. Eye Res. 32, 851-861. doi: 10.1080/02713680701585872

MacCormick, I. J., Czanner, G., and Faragher, B. (2015). Developing retinal biomarkers of neurological disease: an analytical perspective. Biomark. Med. 9 , 691-701. doi: 10.2217/bmm.15.17

Mafei, L., and Fiorentini, A. (1981). Electroretinographic responses to alternating gratings before and after section of the optic nerve. Science 211, 953-955. doi: $10.1126 /$ science. 7466369

Marziani, E., Pomati, S., Ramolfo, P., Cigada, M., Giani, A., Mariani, C., et al. (2013). Evaluation of retinal nerve fiber layer and ganglion cell layer thickness in Alzheimer's disease using spectral-domain optical coherence tomography. Invest. Ophthalmol. Vis. Sci 54, 5953-5958. doi: 10.1167/iovs.1312046

Masters, C. L., Simms, G., Weinman, N. A., Multhaup, G., McDonald, B. L., and Beyreuther, K. (1985). Amyloid plaque core protein in Alzheimer disease and Down syndrome. Proc. Natl. Acad. Sci. U.S.A. 82, 4245-4249. doi: 10.1073/pnas. 82.12.4245

McKhann, G., Drachman, D., Folstein, M., Katzman, R., Price, D., and Stadlan, E. M. (1984). Clinical diagnosis of Alzheimer's disease: report of the NINCDSADRDA work group under the auspices of department of health and human services task force on Alzheimer's disease. Neurology 34, 939-944. doi: 10.1212/ WNL.34.7.939

Meyer-Luehmann, M., Spires-Jones, T. L., Prada, C., Garcia-Alloza, M., de Calignon, A., Rozkalne, A., et al. (2008). Rapid appearance and local toxicity of amyloid-beta plaques in a mouse model of Alzheimer's disease. Nature 451, 720-724. doi: 10.1038/nature06616

Moore, K. M., Girens, R. E., Larson, S. K., Jones, M. R., Restivo, J. L., Holtzman, D. M., et al. (2016). A spectrum of exercise training reduces soluble Abeta in a dose-dependent manner in a mouse model of Alzheimer's disease. Neurobiol. Dis. 85, 218-224. doi: 10.1016/j.nbd.2015.11.004

Moreno-Ramos, T., Benito-Leon, J., Villarejo, A., and Bermejo-Pareja, F. (2013). Retinal nerve fiber layer thinning in dementia associated with Parkinson's disease, dementia with Lewy bodies, and Alzheimer's disease. J. Alzheimers Dis. 34, 659-664. doi: 10.3233/JAD- 121975

Morin, P. J., Abraham, C. R., Amaratunga, A., Johnson, R. J., Huber, G., Sandell, J. H., et al. (1993). Amyloid precursor protein is synthesized by retinal ganglion cells, rapidly transported to the optic nerve plasma membrane and nerve terminals, and metabolized. J. Neurochem. 61, 464-473. doi: 10.1111/j.14714159.1993.tb02147.x

Mwanza, J. C., Durbin, M. K., Budenz, D. L., Sayyad, F. E., Chang, R. T., Neelakantan, A., et al. (2012). Glaucoma diagnostic accuracy of ganglion cell-inner plexiform layer thickness: comparison with nerve fiber layer and optic nerve head. Ophthalmology 119, 1151-1158. doi: 10.1016/j.ophtha.2011. 12.014

Nguyen, U. T., Bhuiyan, A., Park, L. A., Kawasaki, R., Wong, T. Y., Wang, J. J., et al. (2013). Automated quantification of retinal arteriovenous nicking from colour fundus images. Conf. Proc. IEEE Eng. Med. Biol. Soc. 2013, 5865-5868. doi: 10.1109/EMBC.2013.6610886 
Ning, A., Cui, J., To, E., Ashe, K. H., and Matsubara, J. (2008). Amyloidbeta deposits lead to retinal degeneration in a mouse model of Alzheimer disease. Invest. Ophthalmol. Vis. Sci. 49, 5136-5143. doi: 10.1167/iovs.081849

Olafsdottir, O. B., Saevarsdottir, H. S., Hardarson, S. H., Hannesdottir, K. H., Traustadottir, V. D., Karlsson, R. A., et al. (2018). Retinal oxygen metabolism in patients with mild cognitive impairment. Alzheimers Dement. 10, 340-345. doi: 10.1016/j.dadm.2018.03.002

Ong, Y. T., Hilal, S., Cheung, C. Y., Xu, X., Chen, C., Venketasubramanian, N., et al. (2014). Retinal vascular fractals and cognitive impairment. Dement. Geriatr. Cogn. Dis. Extra 4, 305-313. doi: 10.1159/000363286

Paquet, C., Boissonnot, M., Roger, F., Dighiero, P., Gil, R., and Hugon, J. (2007). Abnormal retinal thickness in patients with mild cognitive impairment and Alzheimer's disease. Neurosci. Lett. 420, 97-99. doi: 10.1016/j.neulet.2007. 02.090

Parisi, V. (2003). Correlation between morphological and functional retinal impairment in patients affected by ocular hypertension, glaucoma, demyelinating optic neuritis and Alzheimer's disease. Semin. Ophthalmol. $18,50-57$.

Parisi, V., Restuccia, R., Fattapposta, F., Mina, C., Bucci, M. G., and Pierelli, F. (2001). Morphological and functional retinal impairment in Alzheimer's disease patients. Clin. Neurophysiol. 112, 1860-1867. doi: 10.1016/S1388-2457(01) 00620-4

Park, S. W., Kim, J. H., Mook-Jung, I., Kim, K. W., Park, W. J., Park, K. H., et al. (2014). Intracellular amyloid beta alters the tight junction of retinal pigment epithelium in 5XFAD mice. Neurobiol. Aging 35, 2013-2020. doi: 10.1016/j. neurobiolaging.2014.03.008

Parnell, M., Guo, L., Abdi, M., and Cordeiro, M. F. (2012). Ocular manifestations of Alzheimer's disease in animal models. Int. J. Alzheimers Dis. 2012:786494. doi: 10.1155/2012/786494

Pase, M. P., Herbert, A., Grima, N. A., Pipingas, A., and O’Rourke, M. F. (2012). Arterial stiffness as a cause of cognitive decline and dementia: a systematic review and meta-analysis. Intern. Med. J. 42, 808-815. doi: 10.1111/j.1445-5994. 2011.02645.x

Patton, N., Pattie, A., MacGillivray, T., Aslam, T., Dhillon, B., Gow, A., et al. (2007). The association between retinal vascular network geometry and cognitive ability in an elderly population. Invest. Ophthalmol. Vis. Sci. 48, 1995-2000. doi: 10. 1167/iovs.06-1123

Perez, S. E., Lumayag, S., Kovacs, B., Mufson, E. J., and Xu, S. (2009). Beta-amyloid deposition and functional impairment in the retina of the APPswe/PS1DeltaE9 transgenic mouse model of Alzheimer's disease. Invest. Ophthalmol. Vis. Sci. 50, 793-800. doi: 10.1167/iovs.08-2384

Polanco, J. C., Li, C., Bodea, L. G., Martinez-Marmol, R., Meunier, F. A., and Gotz, J. (2018). Amyloid-beta and tau complexity - towards improved biomarkers and targeted therapies. Nat. Rev. Neurol. 14, 22-39. doi: 10.1038/nrneurol.2017.162

Polo, V., Garcia-Martin, E., Bambo, M. P., Pinilla, J., Larrosa, J. M., Satue, M., et al. (2014). Reliability and validity of Cirrus and Spectralis optical coherence tomography for detecting retinal atrophy in Alzheimer's disease. Eye 28, 680690. doi: 10.1038/eye.2014.51

Prince, M., Wimo, A., Guerchet, M., Claire, A., YuTzu, W., and Matthew, P. (2015). World Alzheimer Report 2015: The Global Impact of Dementia: An Analysis of Prevalence, Incidence, Cost and Trends. London: Alzheimer's Disease International.

Puliafito, C. A., Hee, M. R., Lin, C. P., Reichel, E., Schuman, J. S., Duker, J. S., et al. (1995). Imaging of macular diseases with optical coherence tomography. Ophthalmology 102, 217-229. doi: 10.1016/S0161-6420(95) 31032-9

Qiu, C., Cotch, M. F., Sigurdsson, S., Jonsson, P. V., Jonsdottir, M. K., Sveinbjrnsdottir, S., et al. (2010). Cerebral microbleeds, retinopathy, and dementia: the AGES-Reykjavik study. Neurology 75, 2221-2228. doi: 10.1212/ WNL.0b013e3182020349

Ran, C., Xu, X., Raymond, S. B., Ferrara, B. J., Neal, K., Bacskai, B. J., et al. (2009). Design, synthesis, and testing of difluoroboron-derivatized curcumins as nearinfrared probes for in vivo detection of amyloid-beta deposits. J. Am. Chem. Soc. 131, 15257-15261. doi: 10.1021/ja9047043

Rohrschneider, K., Bultmann, S., and Springer, C. (2008). Use of fundus perimetry (microperimetry) to quantify macular sensitivity. Prog. Retin. Eye Res. 27, 536-548. doi: 10.1016/j.preteyeres.2008.07.003
Ruitenberg, A., den Heijer, T., Bakker, S. L., van Swieten, J. C., Koudstaal, P. J., Hofman, A., et al. (2005). Cerebral hypoperfusion and clinical onset of dementia: the Rotterdam study. Ann. Neurol. 57, 789-794. doi: 10.1002/ana. 20493

Salloway, S., Sperling, R., Fox, N. C., Blennow, K., Klunk, W., Raskind, M., et al. (2014). Two phase 3 trials of bapineuzumab in mild-to-moderate Alzheimer's disease. N. Engl. J. Med. 370, 322-333. doi: 10.1056/NEJMoa130 4839

Salobrar-Garcia, E., Hoyas, I., Leal, M., de Hoz, R., Rojas, B., Ramirez, A. I., et al. (2015). Analysis of retinal peripapillary segmentation in early Alzheimer's disease patients. Biomed Res. Int. 2015:636548. doi: 10.1155/2015/ 636548

Salt, T. E., Nizari, S., Cordeiro, M. F., Russ, H., and Danysz, W. (2014). Effect of the Abeta aggregation modulator MRZ-99030 on retinal damage in an animal model of glaucoma. Neurotox. Res. 26, 440-446. doi: 10.1007/s12640-0149488-6

Santos, C. Y., Johnson, L. N., Sinoff, S. E., Festa, E. K., Heindel, W. C., and Snyder, P. J. (2018). Change in retinal structural anatomy during the preclinical stage of Alzheimer's disease. Alzheimers Dement. 10, 196-209. doi: 10.1016/j.dadm. 2018.01.003

Schon, C., Hoffmann, N. A., Ochs, S. M., Burgold, S., Filser, S., Steinbach, S., et al. (2012). Long-term in vivo imaging of fibrillar tau in the retina of P301S transgenic mice. PLoS One 7:e53547. doi: 10.1371/journal.pone. 0053547

Schrijvers, E. M., Buitendijk, G. H., Ikram, M. K., Koudstaal, P. J., Hofman, A., Vingerling, J. R., et al. (2012). Retinopathy and risk of dementia: the Rotterdam study. Neurology 79, 365-370. doi: 10.1212/WNL.0b013e3182 $60 \mathrm{~cd} 7 \mathrm{e}$

Schuman, S. G., Koreishi, A. F., Farsiu, S., Jung, S. H., Izatt, J. A., and Toth, C. A. (2009). Photoreceptor layer thinning over drusen in eyes with age-related macular degeneration imaged in vivo with spectral-domain optical coherence tomography. Ophthalmology 116, 488.e-496.e. doi: 10.1016/j.ophtha.2008. 10.006

Schwartz, M., Belkin, M., Yoles, E., and Solomon, A. (1996). Potential treatment modalities for glaucomatous neuropathy: neuroprotection and neuroregeneration. J. Glaucoma 5, 427-432. doi: 10.1097/00061198199612000-00012

Sevigny, J., Chiao, P., Bussiere, T., Weinreb, P. H., Williams, L., Maier, M., et al. (2016). The antibody aducanumab reduces Abeta plaques in Alzheimer's disease. Nature 537, 50-56. doi: 10.1038/nature 19323

Siemers, E. R., Sundell, K. L., Carlson, C., Case, M., Sethuraman, G., LiuSeifert, H., et al. (2016). Phase 3 solanezumab trials: secondary outcomes in mild Alzheimer's disease patients. Alzheimers Dement. 12, 110-120. doi: 10.1016/j. jalz.2015.06.1893

Sperling, R. A., Aisen, P. S., Beckett, L. A., Bennett, D. A., Craft, S., Fagan, A. M., et al. (2011a). Toward defining the preclinical stages of Alzheimer's disease: recommendations from the National Institute on Aging-Alzheimer's Association workgroups on diagnostic guidelines for Alzheimer's disease. Alzheimers Dement. 7, 280-292. doi: 10.1016/j.jalz.2011. 03.003

Sperling, R. A., Jack, C. R. Jr., and Aisen, P. S. (2011b). Testing the right target and right drug at the right stage. Sci. Transl. Med. 3:111 cm133. doi: 10.1126/ scitranslmed.3002609

Stefansson, E., Olafsdottir, O. B., Einarsdottir, A. B., Eliasdottir, T. S., Eysteinsson, T., Vehmeijer, W., et al. (2017). Retinal oximetry discovers novel biomarkers in retinal and brain diseases. Invest. Ophthalmol. Vis. Sci. 58, BIO227-BIO233. doi: 10.1167/iovs.17-21776

Strenn, K., Dal-Bianco, P., Weghaupt, H., Koch, G., Vass, C., and Gottlob, I. (1991). Pattern electroretinogram and luminance electroretinogram in Alzheimer's disease. J. Neural Transm. Suppl. 33, 73-80. doi: 10.1007/978-3-70919135-4_12

Tan, O., Chopra, V., Lu, A. T., Schuman, J. S., Ishikawa, H., Wollstein, G., et al. (2009). Detection of macular ganglion cell loss in glaucoma by Fourierdomain optical coherence tomography. Ophthalmology 116, 2305.e2-2314.e2. doi: 10.1016/j.ophtha.2009.05.025

Taylor, A. M., MacGillivray, T. J., Henderson, R. D., Ilzina, L., Dhillon, B., Starr, J. M., et al. (2015). Retinal vascular fractal dimension, childhood IQ, and 
cognitive ability in old age: the Lothian Birth Cohort Study 1936. PLoS One 10:e0121119. doi: 10.1371/journal.pone.0121119

Terry, R. D., DeTeresa, R., and Hansen, L. A. (1987). Neocortical cell counts in normal human adult aging. Ann. Neurol. 21, 530-539. doi: 10.1002/ana. 410210603

Thomson, K. L., Yeo, J. M., Waddell, B., Cameron, J. R., and Pal, S. (2015). A systematic review and meta-analysis of retinal nerve fiber layer change in dementia, using optical coherence tomography. Alzheimers Dement. 1, 136-143. doi: 10.1016/j.dadm.2015.03.001

Trick, G. L., Barris, M. C., and Bickler-Bluth, M. (1989). Abnormal pattern electroretinograms in patients with senile dementia of the Alzheimer type. Ann. Neurol. 26, 226-231. doi: 10.1002/ana.410260208

Tsai, C. S., Ritch, R., Schwartz, B., Lee, S. S., Miller, N. R., Chi, T., et al. (1991). Optic nerve head and nerve fiber layer in Alzheimer's disease. Arch. Ophthalmol. 109, 199-204. doi: 10.1001/archopht.1991.01080020045040

Vecino, E., Rodriguez, F. D., Ruzafa, N., Pereiro, X., and Sharma, S. C. (2016). Glianeuron interactions in the mammalian retina. Prog. Retin. Eye Res. 51, 1-40. doi: $10.1016 /$ j.preteyeres.2015.06.003

Walton, O. B., Garoon, R. B., Weng, C. Y., Gross, J., Young, A. K., Camero, K. A., et al. (2016). Evaluation of automated teleretinal screening program for diabetic retinopathy. JAMA Ophthalmol. 134, 204-209. doi: 10.1001/jamaophthalmol. 2015.5083

Wang, J., Ohno-Matsui, K., Yoshida, T., Shimada, N., Ichinose, S., Sato, T., et al. (2009). Amyloid-beta up-regulates complement factor B in retinal pigment epithelial cells through cytokines released from recruited macrophages/microglia: another mechanism of complement activation in agerelated macular degeneration. J. Cell. Physiol. 220, 119-128. doi: 10.1002/jcp. 21742

Williams, M. A., McGowan, A. J., Cardwell, C. R., Cheung, C. Y., Craig, D., Passmore, P., et al. (2015). Retinal microvascular network attenuation in Alzheimer's disease. Alzheimers Dement. 1, 229-235. doi: 10.1016/j.dadm.2015. 04.001
Williams, M. A., Silvestri, V., Craig, D., Passmore, A. P., and Silvestri, G. (2014). The prevalence of age-related macular degeneration in Alzheimer's disease. J. Alzheimers Dis. 42, 909-914. doi: 10.3233/JAD-140243

Wu, Z., Ayton, L. N., Guymer, R. H., and Luu, C. D. (2014). Comparison between multifocal electroretinography and microperimetry in age-related macular degeneration. Invest. Ophthalmol. Vis. Sci. 55, 6431-6439. doi: 10.1167/iovs.1414407

Yip, W., Siantar, R., Perera, S. A., Milastuti, N., Ho, K. K., Tan, B., et al. (2014). Reliability and determinants of retinal vessel oximetry measurements in healthy eyes. Invest. Ophthalmol. Vis. Sci. 55, 7104-7110. doi: 10.1167/iovs.1313854

Yoles, E., and Schwartz, M. (1998). Degeneration of spared axons following partial white matter lesion: implications for optic nerve neuropathies. Exp. Neurol. 153, 1-7. doi: 10.1006/exnr.1998.6811

Zhang-Nunes, S. X., Maat-Schieman, M. L., van Duinen, S. G., Roos, R. A., Frosch, M. P., and Greenberg, S. M. (2006). The cerebral beta-amyloid angiopathies: hereditary and sporadic. Brain Pathol. 16, 30-39. doi: 10.1111/j.1750-3639.2006. tb00559.x

Zlokovic, B. V. (2011). Neurovascular pathways to neurodegeneration in Alzheimer's disease and other disorders. Nat. Rev. Neurosci. 12, 723-738. doi: $10.1038 / \mathrm{nrn} 3114$

Conflict of Interest Statement: The authors declare that the research was conducted in the absence of any commercial or financial relationships that could be construed as a potential conflict of interest.

Copyright (c) 2018 Liao, Zhu and Peng. This is an open-access article distributed under the terms of the Creative Commons Attribution License (CC BY). The use, distribution or reproduction in other forums is permitted, provided the original author(s) and the copyright owner are credited and that the original publication in this journal is cited, in accordance with accepted academic practice. No use, distribution or reproduction is permitted which does not comply with these terms. 